\title{
Glucagon-Like Peptide 1 Receptor Agonist Usage in Type 2 Diabetes in Primary Care for the UK and Beyond: A Narrative Review
}

\author{
Kevin Fernando (D) - Stephen C. Bain · Patrick Holmes • \\ Philip Newland Jones · Dipesh C. Patel
}

Received: March 26, 2021 / Accepted: July 7, 2021 / Published online: July 26, 2021

(C) The Author(s) 2021

\begin{abstract}
The scientific landscape of treatments for type 2 diabetes (T2D) has changed rapidly in the last decade with newer treatments becoming available. However, a large proportion of people with T2D are not able to achieve glycaemic goals because of clinical inertia. The majority of T2D management is in primary care, where clinicians (medical, nursing and pharmacist staff) play an important role in addressing patient needs and achieving treatment goals. However, management of $\mathrm{T} 2 \mathrm{D}$ is challenging because of the heterogeneity of T2D and complexity of comorbidity, time constraints, guidance overload and the evolving treatments.
\end{abstract}

K. Fernando ( $\square)$

North Berwick Health Centre, North Berwick Group

Practice, 54 St. Baldred's Road,

North Berwick EH39 4PU, UK

e-mail: kevinfernando@doctors.org.uk

S. C. Bain

Diabetes Research Unit, Swansea University,

Swansea, UK

P. Holmes

St. Georges Medical Practice, Darlington, UK

P. N. Jones

University Hospitals Southampton NHS Foundation

Trust, Southampton, UK

D. C. Patel

University College London, Royal Free Campus, London, UK
Additionally, the current coronavirus disease pandemic poses additional challenges to the management of chronic diseases such as T2D, including routine access to patients for monitoring and communication. Glucagon-like peptide 1 receptor agonists (GLP-1 RAs) are a class of agents that have evolved rapidly in recent years. These agents act in a glucose-dependent manner to promote insulin secretion and inhibit glucagon secretion, as well as enhancing satiety and reducing hunger. As a result, they are effective treatment options for people with T2D, achieving glycated haemoglobin reductions, weight loss and potential cardiovascular benefit, as monotherapy or as add-on to other glucose-lowering therapies. However, given the complexity of managing $\mathrm{T} 2 \mathrm{D}$, it is important to equip primary care clinicians with clear information regarding efficacy, safety and appropriate positioning of GLP-1 RA therapies in clinical practice. This review provides a summary of clinical and realworld evidence along with practical guidance, with the aim of aiding primary care clinicians in the initiation and monitoring of GLP-1 RAs to help ensure that desired outcomes are realised. Furthermore, a benefit/risk tool has been developed on the basis of current available evidence and guidelines to support primary care clinicians in selecting individuals who are most likely to benefit from GLP-1 RA therapies, in addition to indicating clinical situations where caution is needed. 
Keywords: Clinical guidance; Glucagon-like peptide 1 receptor agonist; Glucose-lowering medicines; Prescribing tools; Primary care; Risk/benefit; Therapy choice; Type 2 diabetes

\section{Key Summary Points}

Management of type 2 diabetes (T2D) in primary care is challenging because of the complexity of T2D, time constraints, guidance overload, evolving treatments and the current coronavirus disease pandemic.

Glucagon-like peptide 1 receptor agonists (GLP1 RAs) are an effective treatment option in primary care for people with $\mathrm{T} 2 \mathrm{D}$, achieving $\mathrm{HbA}_{1 \mathrm{c}}$ reductions, weight loss and potential cardiovascular benefit, as monotherapy or as add-on to other glucose-lowering therapies.

This review provides a summary of clinical and real-world evidence along with practical guidance, with the aim of aiding primary care clinicians in the initiation and monitoring of GLP-1 RAs to ensure desired outcomes.

Furthermore, a benefit/risk tool has been developed to support primary care clinicians in selecting individuals who are most likely to benefit from GLP-1 RA therapies, in addition to indicating clinical situations where caution is needed.

\section{INTRODUCTION}

Despite the availability of new treatments over the last decade, a large proportion of people with type 2 diabetes (T2D) are not able to achieve their glycaemic goals $[1,2]$ because of clinical inertia (failure to begin or intensify treatment despite not reaching therapeutic goals) [3]. The reasons for clinical inertia are complex, with a range of contributing factors from people with T2D, physicians and the healthcare delivery system [3]. The commonly cited factors for people with T2D and physicians include fear of hypoglycaemia, weight gain and the plethora of treatment options with increasing management complexity [3]. The majority of T2D management is in primary care [4], where clinicians (medical, nursing and pharmacist staff) are uniquely placed to use their generalist expertise to partner with individuals with $\mathrm{T} 2 \mathrm{D}$ to develop a treatment plan to address their needs and help achieve treatment goals. However, the decision-making process in primary care is challenging, given the complexity of T2D due to comorbidities, time constraints, guidance overload and the changing scientific landscape of available treatments [3]. It is, therefore, important to provide primary care clinicians with the clinical evidence as well as a simple and pragmatic tool that could aid the decision-making process.

In addition, the ongoing coronavirus disease (Covid-19) pandemic poses additional challenges to primary care, especially the management of chronic diseases such as T2D [5]. Virtual healthcare and digital technologies have become critical to allow healthcare professionals to carry out routine consultations. However, these also bring significant technical and logistical challenges. As such, there is a need to provide primary care clinicians with clear guidance concerning virtual healthcare in order to adapt to limited face-to-face interactions and help optimise interventions in healthcare.

Glucagon-like peptide 1 receptor agonists (GLP-1 RAs) have been studied extensively in the last decade and are well suited for the management of T2D in primary and secondary care, owing to their glucose-lowering and weight-loss properties and low intrinsic risk of hypoglycaemia, as well as cardiovascular (CV) benefits [6,7]. The aim of this review is to summarise the clinical evidence, including efficacy and safety concerning the use of GLP-1 RAs, and provide practical guidance for clinicians regarding initiation and use of GLP-1 RAs in the treatment of T2D.

This article is based on previously conducted studies and does not contain any studies with 
human participants or animals performed by any of the authors.

\section{THE GLP-1 RA CLASS OF MEDICINES}

\section{Mechanism of Action of GLP-1 and Its Receptor Agonists}

The incretin peptide hormone GLP-1 is secreted from the lower gastrointestinal (GI) tract into the circulation within minutes of food ingestion $[6,8]$. Signalling via its receptors located in various organs, including brain, GI tract and pancreas [9-11], GLP-1 provides a number of effects in the setting of T2D [11]. In the pancreas, GLP-1 receptors act in a glucose-dependent manner to prompt insulin secretion and inhibit glucagon secretion [8, 12, 13]. Apart from the well-known pancreatic effect, GLP-1 enhances satiety and reduces hunger by acting on both central and peripheral receptors in the brain and GI tract [14]. As a result of all of these potentially beneficial effects, GLP-1 RAs are suitable for the treatment of T2D.

\section{Overview of Available GLP-1 RAs in the UK and Europe}

A number of GLP-1 RAs have been approved in the UK and Europe for the treatment of T2D (Table 1). As a result of being peptides, GLP-1 RAs typically have to be given by subcutaneous (s.c.) administration as twice daily (BID) (exenatide) $[15,16]$, once daily (OD) (lixisenatide $[17,18]$ and liraglutide $[19,20])$ or once weekly (OW) (dulaglutide [21, 22], prolonged-release exenatide [23, 24] and semaglutide [25, 26]) dosing regimens, based on their in vivo halflives [6]. Further to these, a novel OD oral formulation of semaglutide was launched in September 2020 in the UK and Europe [27, 28], as an alternative to the OW s.c. formulation of the same drug.

Because of the differences in product half-life and therefore dosing interval, GLP-1 RAs can be classified as short- or long-acting [6]. Short-acting formulations include exenatide BID (with a
Table 1 Overview of available GLP-1 RAs available in the UK and Europe for the treatment of T2D

\begin{tabular}{|c|c|c|}
\hline $\begin{array}{l}\text { Generic } \\
\text { (trade) name }\end{array}$ & $\begin{array}{l}\text { Recommended } \\
\text { dosage }\end{array}$ & $\begin{array}{l}\text { Available dosage } \\
\text { forms }\end{array}$ \\
\hline $\begin{array}{l}\text { Exenatide } \\
\text { BID } \\
\text { (Byetta) } \\
{[15,16]}\end{array}$ & $\begin{array}{l}5 \mu \mathrm{g} \text { s.c. BID } \\
\text { within } 60 \text { min } \\
\text { prior to the } \\
\text { morning and } \\
\text { evening meals } \\
\text { ( } \geq 6 \mathrm{~h} \text { apart); } \\
\text { after at least } \\
1 \text { month, can } \\
\text { increase to } \\
10 \mu \mathrm{g} \text { s.c. BID to } \\
\text { further improve } \\
\text { glycaemic control }\end{array}$ & $\begin{array}{l}5 \text { and } 10 \mu \mathrm{g} \text { pre- } \\
\text { filled pens } \\
(250 \mu \mathrm{g} / \mathrm{mL}, 60 \\
\text { doses in } 1.2 \text { and } \\
2.4 \mathrm{~mL} \text { solution, } \\
\text { respectively) }\end{array}$ \\
\hline $\begin{array}{l}\text { Lixisenatide } \\
\text { OD } \\
\text { (Lyxumia) } \\
{[17,18]}\end{array}$ & $\begin{array}{l}10 \mu \mathrm{g} \text { s.c. OD } \\
\text { within } 1 \mathrm{~h} \text { before } \\
\text { any meal of the } \\
\text { day for } 14 \text { days; } \\
\text { increase to } 20 \mu \mathrm{g} \\
\text { OD on day } 15\end{array}$ & $\begin{array}{l}10 \text { and } 20 \mu \mathrm{g} \text { pre- } \\
\text { filled pens }(50 \\
\text { and } 100 \mu \mathrm{g} / \mathrm{mL} \text {, } \\
\text { respectively; } 14 \\
\text { doses in } 3 \mathrm{~mL} \\
\text { solution) }\end{array}$ \\
\hline $\begin{array}{l}\text { Liraglutide } \\
\text { OD } \\
\text { (Victoza) } \\
\quad[19,20]\end{array}$ & $\begin{array}{l}0.6 \mathrm{mg} \text { s.c. OD at } \\
\text { any time of the } \\
\text { day, } \\
\text { independently of } \\
\text { meals; after at } \\
\text { least } 1 \text { week, } \\
\text { increase to } \\
1.2 \text { mg; after at } \\
\text { least another } \\
\text { week, may } \\
\text { increase to } \\
1.8 \text { mg to further } \\
\text { improve } \\
\text { glycaemic control }\end{array}$ & $\begin{array}{l}6 \mathrm{mg} / \mathrm{mL} \text { pre-filled, } \\
\text { multi-dose pen } \\
\text { delivers doses of } \\
0.6,1.2 \text { and } \\
1.8 \mathrm{mg} \text { (18 } \mathrm{mg} \\
\text { liraglutide in } \\
3 \mathrm{~mL} \text { solution) }\end{array}$ \\
\hline
\end{tabular}


Table 1 continued

\begin{tabular}{|c|c|c|}
\hline $\begin{array}{l}\text { Generic } \\
\text { (trade) name }\end{array}$ & $\begin{array}{l}\text { Recommended } \\
\text { dosage }\end{array}$ & $\begin{array}{l}\text { Available dosage } \\
\text { forms }\end{array}$ \\
\hline $\begin{array}{l}\text { Dulaglutide } \\
\text { OW } \\
\text { (Trulicity) } \\
{[21,22]}\end{array}$ & $\begin{array}{l}0.75 \text { mg s.c. OW as } \\
\text { monotherapy; } \\
1.5 \mathrm{mg} \text { s.c. OW } \\
\text { as add-on } \\
\text { therapy, } \\
\text { administered at } \\
\text { any time of day, } \\
\text { with or without } \\
\text { meals; the } 1.5 \mathrm{mg} \\
\text { dose may be } \\
\text { increased after at } \\
\text { least } 4 \text { weeks to } \\
3 \text { mg OW and } \\
\text { after at least } \\
\text { another } 4 \text { weeks, } \\
\text { may be increased } \\
\text { to } 4.5 \text { mg OW } \\
\text { for additional } \\
\text { glycaemic control }\end{array}$ & $\begin{array}{l}0.75,1.5,3 \text { and } \\
4.5 \mathrm{mg} \text { single- } \\
\text { dose pen }(0.75, \\
1.5,3 \text { and } \\
4.5 \mathrm{mg} / 0.5 \mathrm{~mL}, \\
\text { respectively) }\end{array}$ \\
\hline $\begin{array}{c}\text { Exenatide } \\
\text { OW } \\
\text { (Bydureon) } \\
{[23,24]}\end{array}$ & $\begin{array}{l}2 \text { mg s.c. OW, } \\
\text { administered at } \\
\text { any time of the } \\
\text { day on the same } \\
\text { day each week, } \\
\text { with or without } \\
\text { meals }\end{array}$ & $\begin{array}{l}\text { Single-use } 2 \mathrm{mg} \text { vial } \\
\text { and } 2 \mathrm{mg} \text { pre- } \\
\text { filled pen with } \\
\text { solvent supplied } \\
\text { for suspension } \\
(0.65 \mathrm{~mL})\end{array}$ \\
\hline $\begin{array}{l}\text { Semaglutide } \\
\text { OW } \\
\text { (Ozempic) } \\
{[25,26]}\end{array}$ & $\begin{array}{l}0.25 \text { mg s.c. OW } \\
\text { administered at } \\
\text { any time of the } \\
\text { day, with or } \\
\text { without meals; } \\
\text { after } 4 \text { weeks, } \\
\text { increase to } \\
0.5 \text { mg OW; } \\
\text { after at least } \\
\text { another } 4 \text { weeks, } \\
\text { may increase to } \\
1.0 \text { mg OW to } \\
\text { improve } \\
\text { glycaemic control }\end{array}$ & $\begin{array}{l}0.25 \text { and } 0.5 \mathrm{mg} \\
\text { pre-filled pens } \\
\text { ( } 2 \mathrm{mg} \\
\text { semaglutide in } \\
1.5 \mathrm{~mL} \text { solution); } \\
1.0 \mathrm{mg} \text { pre-filled } \\
\text { pen ( } 4 \mathrm{mg} \\
\text { semaglutide in } \\
3.0 \mathrm{~mL} \text { solution) }\end{array}$ \\
\hline
\end{tabular}

Table 1 continued

\begin{tabular}{|c|c|c|}
\hline $\begin{array}{l}\text { Generic } \\
\text { (trade) name }\end{array}$ & $\begin{array}{l}\text { Recommended } \\
\text { dosage }\end{array}$ & $\begin{array}{l}\text { Available dosage } \\
\text { forms }\end{array}$ \\
\hline $\begin{array}{l}\text { Oral } \\
\text { semaglutide } \\
\text { OD } \\
\text { (Rybelsus) } \\
{[27,28]}\end{array}$ & $\begin{array}{l}3 \text { mg OD } \\
\text { administered } \\
\text { orally at any time } \\
\text { of the day, for } \\
1 \text { month, and } \\
\text { increase to a } \\
\text { maintenance } \\
\text { dose of } 7 \text { mg; } \\
\text { after at least } \\
1 \text { month, the } \\
\text { dose can be } \\
\text { increased to } \\
14 \text { mg to further } \\
\text { improve } \\
\text { glycaemic control }\end{array}$ & $\begin{array}{l}3,7 \text { and } 14 \mathrm{mg} \\
\text { tablets }\end{array}$ \\
\hline
\end{tabular}

$B I D$ twice daily, GLP-1 RA glucagon-like peptide 1 receptor agonist, $O D$ once daily, $O W$ once weekly, s.c. subcutaneously, $T 2 D$ type 2 diabetes

half-life of $2.4 \mathrm{~h}$ ) and lixisenatide (with a halflife of approximately $3 \mathrm{~h}$ ) [6]. Long-acting GLP1 RAs include liraglutide (with a half-life of $13 \mathrm{~h}$ ), exenatide OW (a prolonged-release formulation of the active drug from poly[D,L-lactide-co-glycolide] microspheres) and dulaglutide (with a half-life of 4.7 days) [21, 22], and s.c. semaglutide formulation (with a half-life of 7 days) $[6,29]$.

Over the last decade, although the prescription of GLP-1 RAs has increased slightly, overall usage remains low compared with other glucose-lowering medications, such as metformin, sulfonylureas and dipeptidyl peptidase 4 inhibitors (DPP4i), regardless of CV disease status [30-33]. A UK analysis described class-level prescribing of glucose-lowering medications in people with T2D and showed a small increase in the prescription of GLP-1 RA from 2017 to 2020 [30]. The proportion of people treated with GLP-1 RA was approximately $6 \%$ for dual 
therapy and $17 \%$ for triple therapy in December 2019 [30]. Despite the CV benefits of some GLP1 RAs [34-38], there was no difference in the prescribing rates of GLP-1 RAs between people with and without CV disease history [30]. In a Danish nationwide cohort study in people with a new dual diagnosis of T2D and CV disease, the number of people prescribed a GLP-1 RA within a year of diagnosis increased from 3.9\% in 2012 to $8.1 \%$ in 2018 [31]. Similarly, on the basis of dispensing data from the Netherlands in people with T2D, the prevalence of treatment with GLP-1 RAs was low (1.2\%) between 2012 and 2017, although it did show an increasing trend over time [33]. In contrast, a negligible reduction in GLP-1 RA use was reported in people with T2D who experienced a CV event between 2010 and 2018, on the basis of an Italian retrospective analysis of electronic health records [32]. The authors of this review speculate that the following factors have contributed to poor uptake of GLP-1 RA therapies: previous cost-effective analyses [39, 40], local clinical guidelines (e.g. National Institute for Health and Care Excellence [NICE] [41]), historical low uptake of injectable medications in primary care [42] and previous prescription of these therapies by specialists. Overall, given the relatively low usage of GLP-1 RAs in the UK and Europe, further clinical evidence and prescribing guidance may be beneficial to encourage the optimised use of GLP-1 RAs.

\section{Clinical Effects of GLP-1 RAs in T2D}

The glycaemic effects, weight reduction and potential CV effects of evolving GLP-1 RAs in the treatment of $\mathrm{T} 2 \mathrm{D}$ have been reviewed extensively in the last decade $[7,11,43]$. The newly available oral semaglutide has also demonstrated robust benefits concerning glycaemia, weight reduction and $\mathrm{CV}$ safety [35, 44-51].

\section{Reduction in Glycated Haemoglobin}

The mean glycated haemoglobin $\left(\mathrm{HbA}_{1 \mathrm{c}}\right)$ changes from baseline associated with GLP-1 RAs reported in clinical studies of T2D and stated in the summary of product characteristics are shown in Fig. 1. In studies of GLP-1 RAs, used as a monotherapy or in combination with other glucose-lowering therapies, mean $\mathrm{HbA}_{1 \mathrm{c}}$ changes from baseline ranged from $-0.2 \%$ to $-1.9 \%(-2.2$ to $-20.9 \mathrm{mmol} / \mathrm{mol})$ (Fig. 1). As a result, these treatments are deemed efficacious for glucose-lowering in people with T2D.

It is important to note that, in patients with long-standing diabetes and insufficient insulin secretory capacity, the glucose-lowering efficacy of GLP-1 RA is likely to be reduced as a result of diminished incretin effects, and concomitant basal insulin treatment may be required [53]. The benefits of combined basal insulin and GLP-1 RAs have been recognised and approved since 2014 [53]. The authors conclude that the therapeutic benefits of GLP-1 RAs are most likely to be seen early in the course of T2D.

\section{Body Weight Reduction}

Body weight reduction was commonly observed in clinical trials evaluating GLP-1 RAs in people with T2D. Average changes in body weight in clinical studies of GLP-1 RAs stated in the summary of product characteristics ranged from +0.9 to $-6.5 \mathrm{~kg}$ (Fig. 2). The weight reduction benefit with GLP-1 RAs, used as a monotherapy or in combination with other glucose-lowering therapies, has been demonstrated in various studies (Fig. 2) and is an important factor for consideration in the treatment of T2D. The only exceptions were with liraglutide $1.2 \mathrm{mg}$ OD and dulaglutide $0.75 \mathrm{mg}$ OW, both of which had occasional weight gains (Fig. 2), possibly due to the concomitant use of insulin or sulfonylurea (SU) in combination therapy [54, 55]. However, observed weight gains were marginally lower than those seen with the comparator medications in the clinical studies $[54,55]$. The weight loss is usually sustainable in the presence of GLP-1 RA treatments, although there is some regain of lost weight upon cessation of GLP-1 RA treatments [14].

\section{Outcomes}

GLP-1 RAs generally improve a number of CV risk markers, including glucose, weight, blood pressure and lipid levels [13, 34-38]. Moreover, 


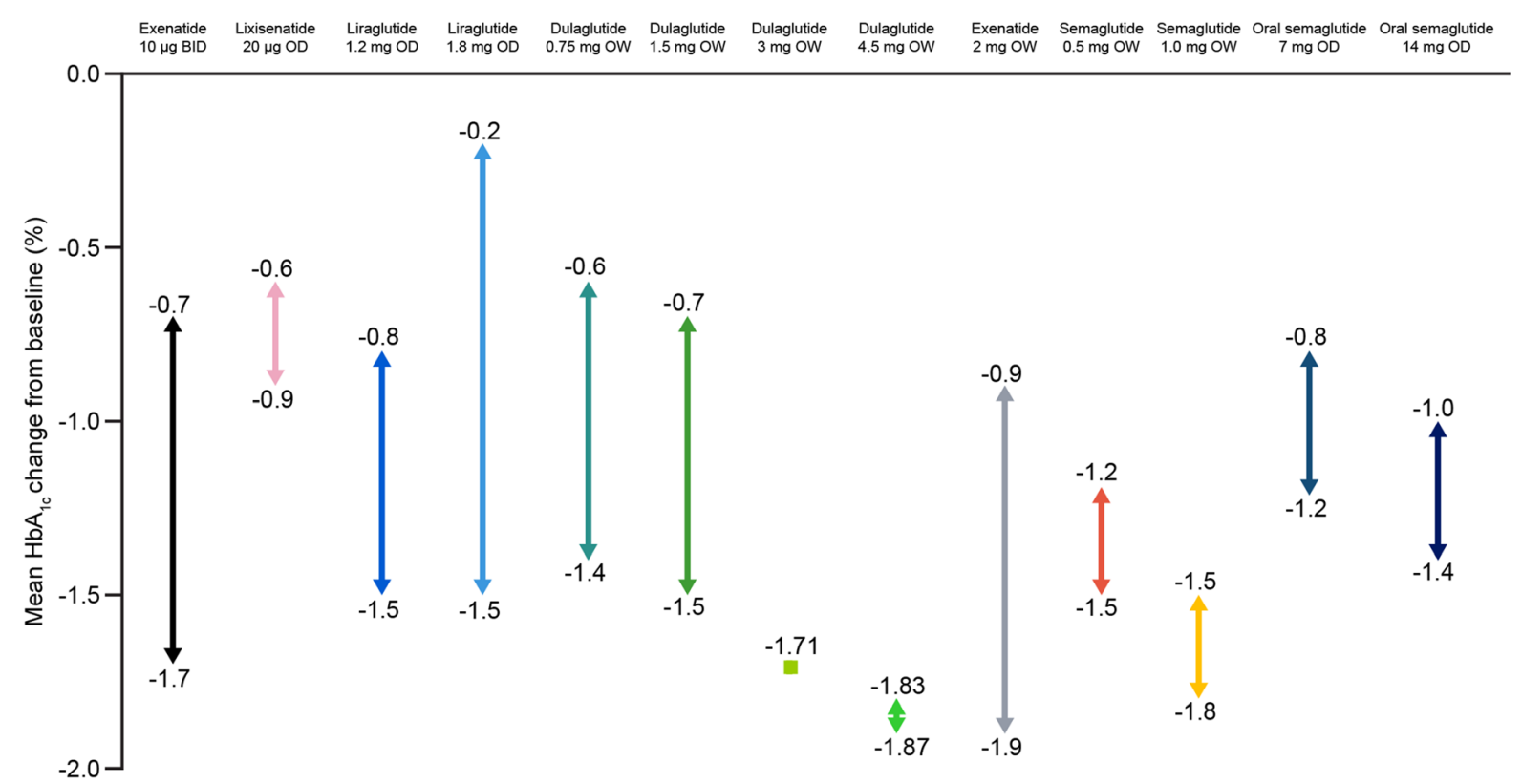

Fig. 1 Range of mean changes from baseline in $\mathrm{HbA}_{1 c}$ in clinical studies reported in the summary of product characteristics for GLP-1 RAs [15, 17, 19, 21, 23, 25, 27, 52]. BID

twice daily, GLP-1 RA glucagon-like peptide 1 receptor agonist, $\mathrm{HbA}_{1 \mathrm{c}}$ glycated haemoglobin, OD once daily, OW once weekly

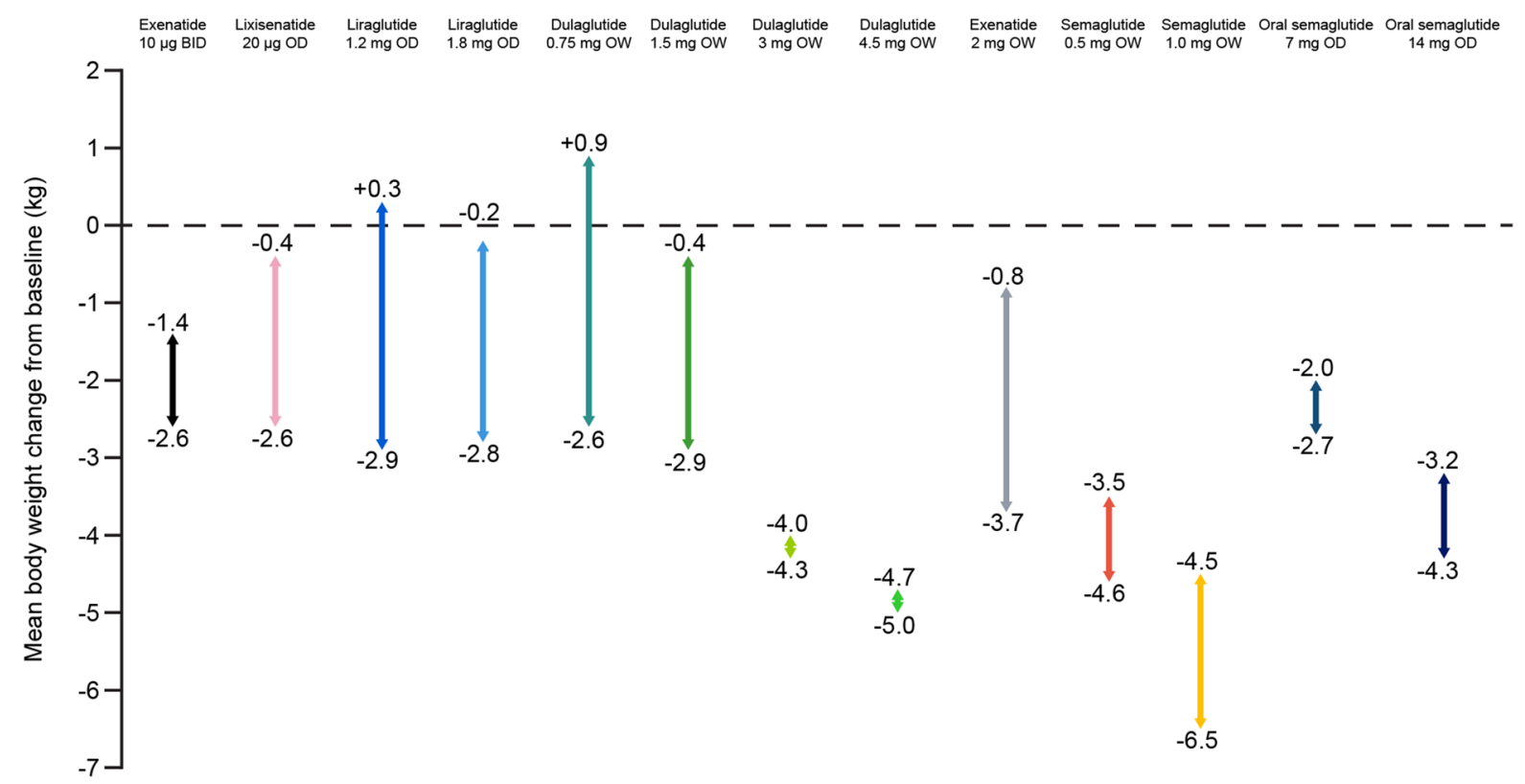

Fig. 2 Range of mean changes from baseline in body weight in clinical studies reported in the summary of product characteristics for GLP-1 RAs [15, 17, 19, 21, 23, 25, 27, 52].

BID twice daily, GLP-1 RA glucagon-like peptide 1 receptor agonist, OD once daily, OW once weekly 
a number of large CV outcome trials (CVOTs) have provided robust evidence concerning $\mathrm{CV}$ outcomes [34-38]. As shown in Fig. 3, significant superiority in primary $\mathrm{CV}$ outcome was observed in three CVOTs using GLP-1 RAs (liraglutide OD in LEADER [56], dulaglutide OW in REWIND [36], and semaglutide $O W$ in SUSTAIN 6 [non-inferiority and superiority were demonstrated in SUSTAIN 6 and pre-specified sensitivity analyses, respectively] [37]). The risks of $\mathrm{CV}$ outcomes associated with exenatide $\mathrm{OW}$ and oral semaglutide OD were shown to be noninferior compared with placebo (Fig. 3); hence, both of these therapies were deemed not to cause an increase in CV risk [34, 35]. Also, lixisenatide OD had a neutral CV profile compared with placebo, but also did not increase the CV risk (Fig. 3) [38].

\section{Safety and Tolerability}

Overall, GLP-1 RAs are well tolerated, with GI symptoms being the most common adverse events (AEs), such as nausea, vomiting, diarrhoea, constipation and abdominal pain; however, most of these events are mild to moderate and their frequency and intensity generally decrease over time $[16,18,20,22,24,26,28]$.

In addition to the above GI AEs, acute pancreatitis was initially reported as an uncommon or rare $\mathrm{AE}$ associated with GLP-1 RAs
$[16,18,20,22,24,26,28]$. A possible mechanism for this link was the development of gallstones associated with significant or rapid weight loss. However, a recent meta-analysis of 43 trials found no association between pancreatitis and GLP-1 RA treatments [57]. Of note, there is an approximately 2-3-fold increased risk of acute pancreatitis in people with T2D, compared with those without T2D [13]. It is therefore advised to avoid these therapies in individuals with a history of pancreatitis.

Although usually only observed when GLP-1 $\mathrm{RA}$ is used in combination with insulin or SU, risk of hypoglycaemia is another reported $\mathrm{AE}$ in people treated with GLP-1 RAs $[16,18,20,22,24,26,28]$. GLP-1 RAs generally have a low intrinsic risk of hypoglycaemia, owing to their glucose-dependent mode of action [7]. Randomised clinical trials have demonstrated very low rates of hypoglycaemia with GLP-1 RAs when used as a monotherapy or in a combination therapy with other glucoselowering drugs [16, 18, 20, 22, 24, 26, 28]. However, when GLP-1 RAs are used in combination with insulin or SU, the dose of these agents should be reduced, in order to reduce the risk of hypoglycaemia [16, 18, 20, 22, 24, 26, 28].

A higher risk of diabetic retinopathy (DR) associated with semaglutide $\mathrm{OW}$ versus placebo was reported in SUSTAIN 6, although this

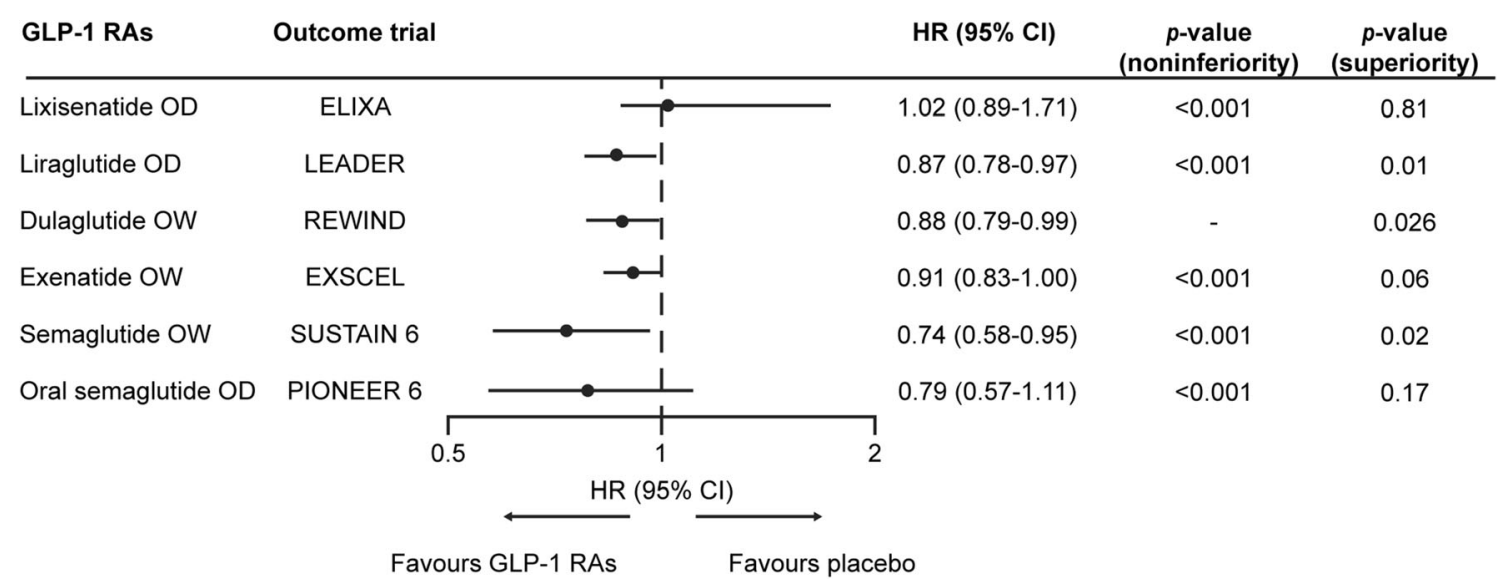

Fig. $3 \mathrm{CV}$ outcomes of GLP-1 RAs versus other glucoselowering agents based on key CV outcome trials $[34-38,56]$. The non-inferiority and superiority of semaglutide OW compared with placebo were demonstrated in SUSTAIN 6 and pre-specified sensitivity analyses, respectively [37]. CI confidence interval, CV cardiovascular, GLP-1 RA glucagon-like peptide 1 receptor agonist, HR hazard ratio, OD once daily, OW once weekly 
increased risk of DR AEs with semaglutide OW versus comparators was not observed in SUSTAIN 1 to 5 or Japanese trials [58]. It was speculated that this increase in DR risk with semaglutide OW in SUSTAIN 6 was due to the large and rapid reduction in $\mathrm{HbA}_{1 \mathrm{c}}$ levels, as observed with other existing therapies [58]. Furthermore, pre-existing DR and insulin use were identified in individuals at high risk of developing DR, and no increased risk of DR with semaglutide $\mathrm{OW}$ versus placebo was observed in those without pre-existing DR, regardless of whether insulin treatment was used [58]. Other AEs include increase in heart rate and injectionsite reactions (excluding oral semaglutide) $[16,18,20,22,24,26]$.

\section{Cost-Effectiveness of GLP-1 RAs Versus Other Medication Classes in Europe}

Cost-effectiveness of GLP-1 RAs versus other medication classes undoubtedly makes an impact on the prescribing behaviour. Sodiumglucose cotransporter 2 inhibitor (SGLT2i) is a class of glucose-lowering agents often compared with GLP-1 RA regarding cost-effectiveness. A long-term (lifetime horizon) modelling analysis found that both liraglutide 1.2 and $1.8 \mathrm{mg}$ OW were cost-effective versus dapagliflozin, with incremental cost-effectiveness ratios (ICERs) within the cost-effectiveness thresholds set by NICE in people with T2D in England and Wales [59]. Furthermore, switching from sitagliptin to liraglutide $1.8 \mathrm{mg} \mathrm{OW}$ in people with poor glycaemic control was likely to be considered costeffective in the UK setting [60]. The recent longterm cost-effectiveness analyses based on the PIONEER trial programme concluded that oral semaglutide was cost-effective versus empagliflozin and sitagliptin in people with T2D in the UK [61]. Similarly, OW semaglutide $0.5 \mathrm{mg}$ and $1 \mathrm{mg}$ were projected to be cost-effective versus empagliflozin $10 \mathrm{mg}$ and $25 \mathrm{mg}$ (an SGLT2i) for the treatment of patients with T2D with inadequate glycaemic control in Spain on the basis of a network meta-analysis of clinical data for the two drugs [62]. In this case, sensitivity analyses revealed the cost-effectiveness to be robust, with semaglutide often being dominant over empagliflozin [62]. Therefore, these GLP-1 RA treatments may be cost-effective alternatives for people with T2D for whom an SGLT2i therapy is considered.

\section{Treatment Guideline Update and Overview}

Based on the available efficacy and safety data, the existing NICE guidelines in the UK recommend that a GLP-1 RA therapy can be considered alongside other glucose-lowering medicines if triple therapy with metformin and two other oral drugs is ineffective, not tolerated or contraindicated [41]. In these situations, NICE recommended that GLP-1 RAs are combined with metformin and an SU [41]. It is suggested that suitable candidates should have a body mass index $(\mathrm{BMI}) \geq 35 \mathrm{~kg} / \mathrm{m}^{2}$ and specific problems associated with obesity, or have a $\mathrm{BMI}<35 \mathrm{~kg} / \mathrm{m}^{2}$ and for whom insulin therapy is not suitable or weight loss is deemed beneficial [41]. GLP-1 RA treatments can be continued if an individual with T2D has had a beneficial metabolic response $\left(\mathrm{HbA}_{1 \mathrm{c}}\right.$ reduction $\geq 1.0 \%[11 \mathrm{mmol} / \mathrm{mol}]$ and weight reduction $\geq 3 \%$ in 6 months) [41]. The Scottish Intercollegiate Guidelines Network (SIGN) recommends GLP-1 RAs to be considered in people with a $B M I \geq 30 \mathrm{~kg} / \mathrm{m}^{2}$ in combination with oral glucose-lowering drugs or basal insulin (or both) as third- or fourth-line treatment, when T2D is uncontrolled on these drugs [63]. If people with T2D are inadequately controlled on oral glucose-lowering drugs, GLP-1 RAs can also be used as an alternative to insulin. Furthermore, GLP-1 RAs with proven CV benefits should be considered in patients with T2D and established CV disease [63]. Figures 4 and 5 present an overview of NICE and SIGN treatment algorithms for blood glucose-lowering and T2D management, respectively [41, 63].

The most recent American Diabetes Association (ADA) guidelines recommend GLP-1 RAs or SGLT2is with proven CV benefits for people with T2D with either established atherosclerotic cardiovascular disease (ASCVD) or indicators of high risk of ASCVD, established kidney disease or heart failure (Fig. 6) [64]. Established ASCVD is defined as prior myocardial infarction, ischaemic stroke, unstable angina with 


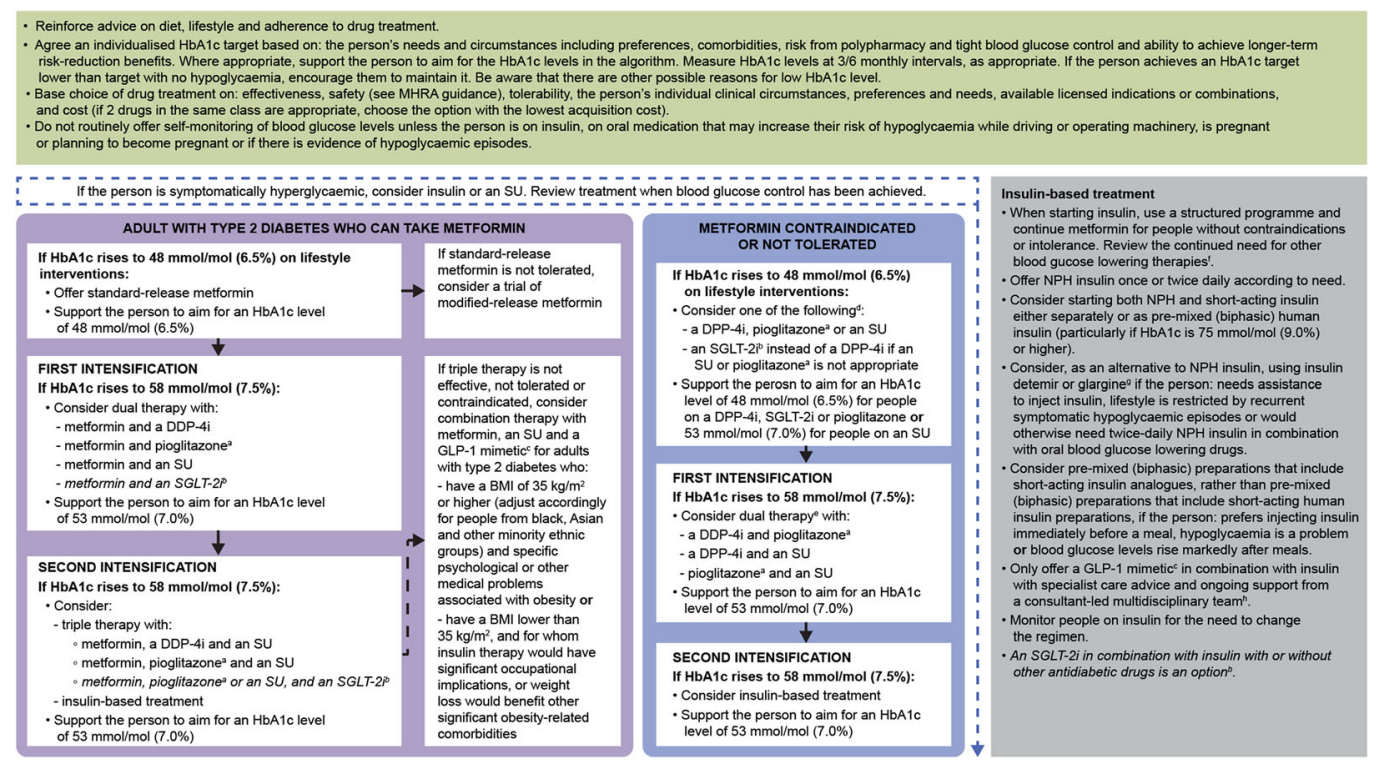

Fig. 4 NICE treatment algorithm for blood glucoselowering therapy in adults with T2D. CNICE [2015] Type 2 diabetes in adults: management NICE guideline [NG28]. [41]. Available from www.nice.org.uk/guidance/ ng28. All rights reserved. Subject to Notice of rights (https:// www.nice.org.uk/terms-and-conditions\#notice-ofrights) NICE guidance is prepared for the National Health Service in England. All NICE guidance is subject to regular review and may be updated or withdrawn. NICE accepts no responsibility for the use of its content in this product/ publication. Recommendations that cover DPP4is, GLP-1 mimetics and SUs refer to these groups of drugs at a class level. ${ }^{\text {a When }}$ prescribing pioglitazone, exercise particular caution if the person is at high risk of the AEs of the drug. Pioglitazone is associated with increased risk of heart failure, bladder cancer and bone fracture. Known risk factors for these conditions, including increased age, should be carefully evaluated before treatment: see the manufacturers' summaries of product characteristics for details. MHRA guidance (2011) advises that 'prescribers should review the safety and efficacy of pioglitazone in individuals after 3-6 months of treatment to ensure that only those deriving benefit continue to be treated'. 'See NICE Technology Appraisal Guidance 288 and 418, 315 and 336 on dapagliflozin, canagliflozin and empagliflozin, respectively. All these SGLT2is are recommended as options in dual therapy regimens with metformin under certain conditions, as options in triple therapy regimens and in combination with insulin. All three are also options as monotherapies in adults in whom metformin is contradicted or not tolerated. Serious and life-threatening cases of DKA have been reported in people taking SGLT2is (canagliflozin, dapagliflozin or empagliflozin) or shortly after stopping the SGLT2i.
MHRA guidance (2015) advises testing for raised ketones in people with DKA symptoms, even if plasma glucose levels are near normal. ${ }^{c}$ Only continue GLP-1 mimetic therapy if the person has a beneficial metabolic response (reduction of $\mathrm{HbA}_{1 \mathrm{c}}$ by at least $1.0 \%[11 \mathrm{mmol} / \mathrm{mol}]$ and weight loss of at least $3 \%$ of initial body weight in 6 months). ${ }^{\text {d If metformin is }}$ contradicted or not tolerated, repaglinide is both clinically effective and cost effective in adults with T2D. However, discuss with any person for whom repaglinide is being considered that there is no licensed non-metformin-based combination containing repaglinide that can be offered at first intensification. ${ }^{\mathrm{e}}$ Drugs in dual therapy should be introduced in a stepwise manner, checking tolerability and effectiveness of each drug. ${ }^{f}$ MHRA guidance (2011) notes that cases of cardiac failure have been reported when pioglitazone was used in combination with insulin, especially in individuals with risk factors for development of cardiac failure. Patients should be observed for signs and symptoms of heart failure, weight gain and oedema. Pioglitazone should be discontinued if any deterioration in cardiac status occurs. ${ }^{g}$ The recommendations in this guideline also apply to any current and future biosimilar product(s) of insulin glargine that have an appropriate marketing authorisation that allows use of the biosimilar(s) in the same indication. AE adverse event, BMI body mass index, DKA diabetic ketoacidosis, DPP4i dipeptidyl peptidase 4 inhibitor, GLP-1 glucagonlike peptide 1, $\mathrm{HbA}_{\mathrm{lc}}$ glycated haemoglobin, MHRA Medicines and Healthcare Products Regulatory Agency, NICE National Institute for Health and Care Excellence, NPH Neutral Protamine Hagedorn, SGLT2i sodium-glucose cotransporter 2 inhibitor, SU sulfonylurea, T2D type 2 diabetes 


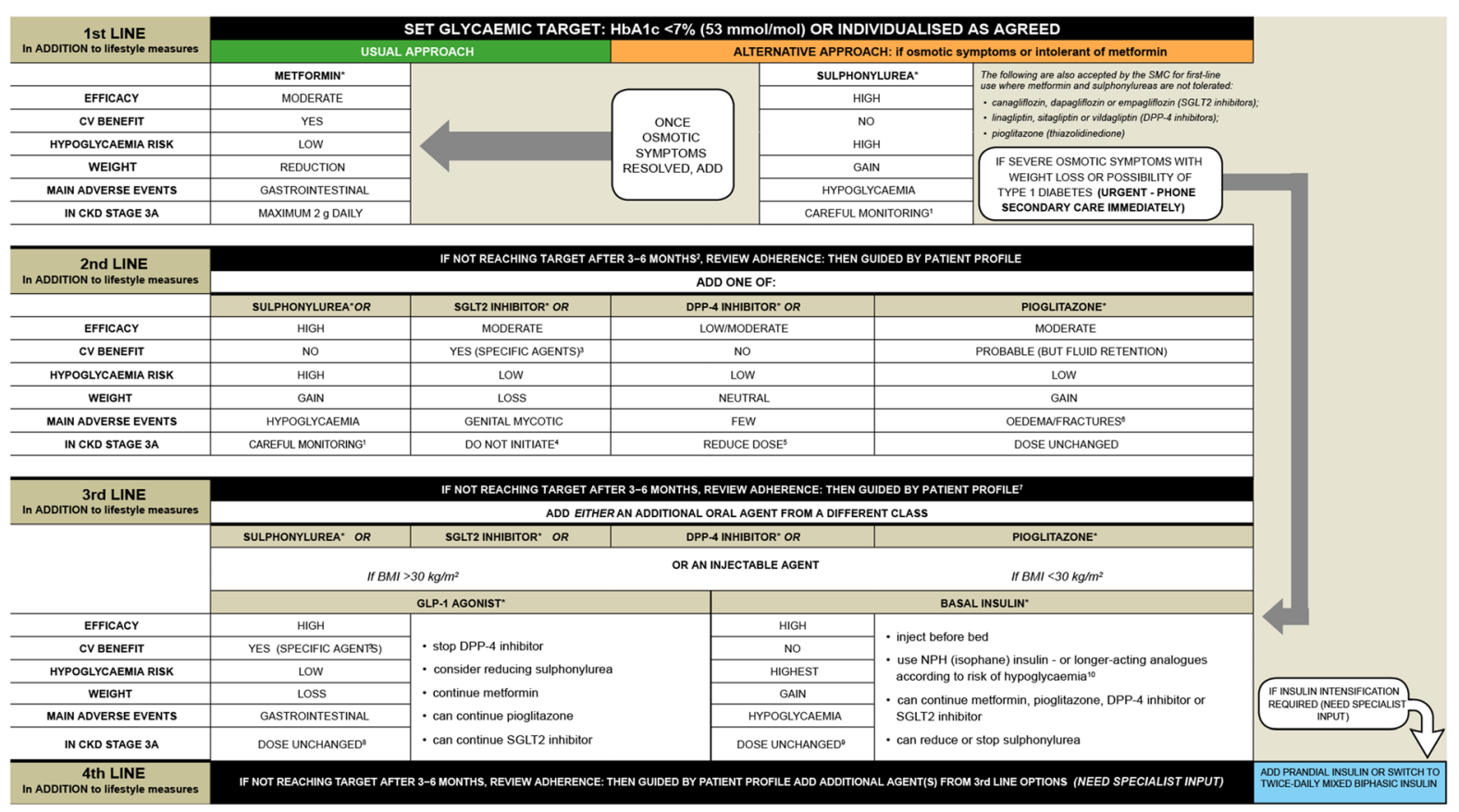

Fig. 5 SIGN treatment algorithm for T2D management. CScottish Intercollegiate Guidelines Network (SIGN). Pharmacological management of glycaemic control in people with type 2 diabetes. Edinburgh: SIGN; 2017. (SIGN publication no. 154). [Accessed 19 Jan 2021]. Available from http://www.sign.ac.uk [63]. Algorithm summarises evidence from the guideline in the context of the clinical experience of the Guideline Development Group. It does not apply in severe renal or hepatic insufficient. Prescribers should refer to the BNF (www. medicinescomplete.com), Scottish Medicines Consortium (www.scottishmedicines.org.uk) and Medicines and Healthcare products Regulatory Agency warnings for updated guidance on licensed indications, full contradictions and monitoring requirements. ${ }^{*}$ Continue medication at each stage if either individual target achieved or $\mathrm{HbA}_{1 \mathrm{c}}$ falls more than $0.5 \%(5.5 \mathrm{mmol} / \mathrm{mol})$ in $3-6$ months; discontinue if evidence that it is ineffective. ${ }^{1}$ Consider dose

electrocardiogram changes, myocardial ischaemia on imaging or stress test, or revascularisation of coronary, carotid or peripheral arteries. Indicators of high ASCVD risk are defined as aged $\geq 55$ years with coronary, carotid or lower extremity artery stenosis $>50 \%$, left ventricular hypertrophy, estimated glomerular filtration rate $<60 \mathrm{~mL} / \mathrm{min} / 1.73 \mathrm{~m}^{2}$ or albuminuria [65]. The ADA/European Association for the Study of Diabetes (EASD) 2019 consensus report reduction. ${ }^{2}$ Do not delay if first-line options not tolerated/ inappropriate. ${ }^{3}$ See guideline pages 23 and $26-27 .{ }^{4}$ See BNF: specific agents can be continued at reduced dose. ${ }^{5}$ See BNF: no dose reduction required for linagliptin. ${ }^{6}$ Pioglitazone is contraindicated in people with (or with history of) HF or bladder cancer. ${ }^{7}$ Do not combine dapagliflozin with pioglitazone. ${ }^{8}$ Caution with exenatide when eGFR $<50 \mathrm{~mL} / \mathrm{min} / 1.73 \mathrm{~m}^{2} .{ }^{9}$ Adjust according to response. ${ }^{10}$ Driving, occupational hazards, risk of falls, previous history. (CKD stage $3 \mathrm{~A}$ is defined as eGFR $45-59 \mathrm{~mL} / \mathrm{min} / 1.73 \mathrm{~m}^{2}$ ). BMI body mass index, BNF British National Formulary, CKD chronic kidney disease, CV cardiovascular, DPP4i dipeptidyl peptidase 4 inhibitor, eGFR estimated glomerular filtration rate, GLP-1 glucagon-like peptide $1, \mathrm{HbA}_{1 \mathrm{c}}$ glycated haemoglobin, HF heart failure, SGLT2i sodium-glucose cotransporter 2 inhibitor, SIGN Scottish Intercollegiate Guidelines Network, T2D type 2 diabetes, $S U$ sulfonylurea

recommended that the decision to use a GLP-1 RA or SGLT2i to treat individuals with high risk of major adverse CV events, hospitalisation for heart failure, $\mathrm{CV}$ death or chronic kidney disease should be independent of baseline $\mathrm{HbA}_{1 \mathrm{c}}$ or individual $\mathrm{HbA}_{1 \mathrm{c}}$ target [65]. GLP-1 RA therapies are also preferred to insulin in people with T2D who need further glucose lowering than can be obtained with oral agents [64]. 


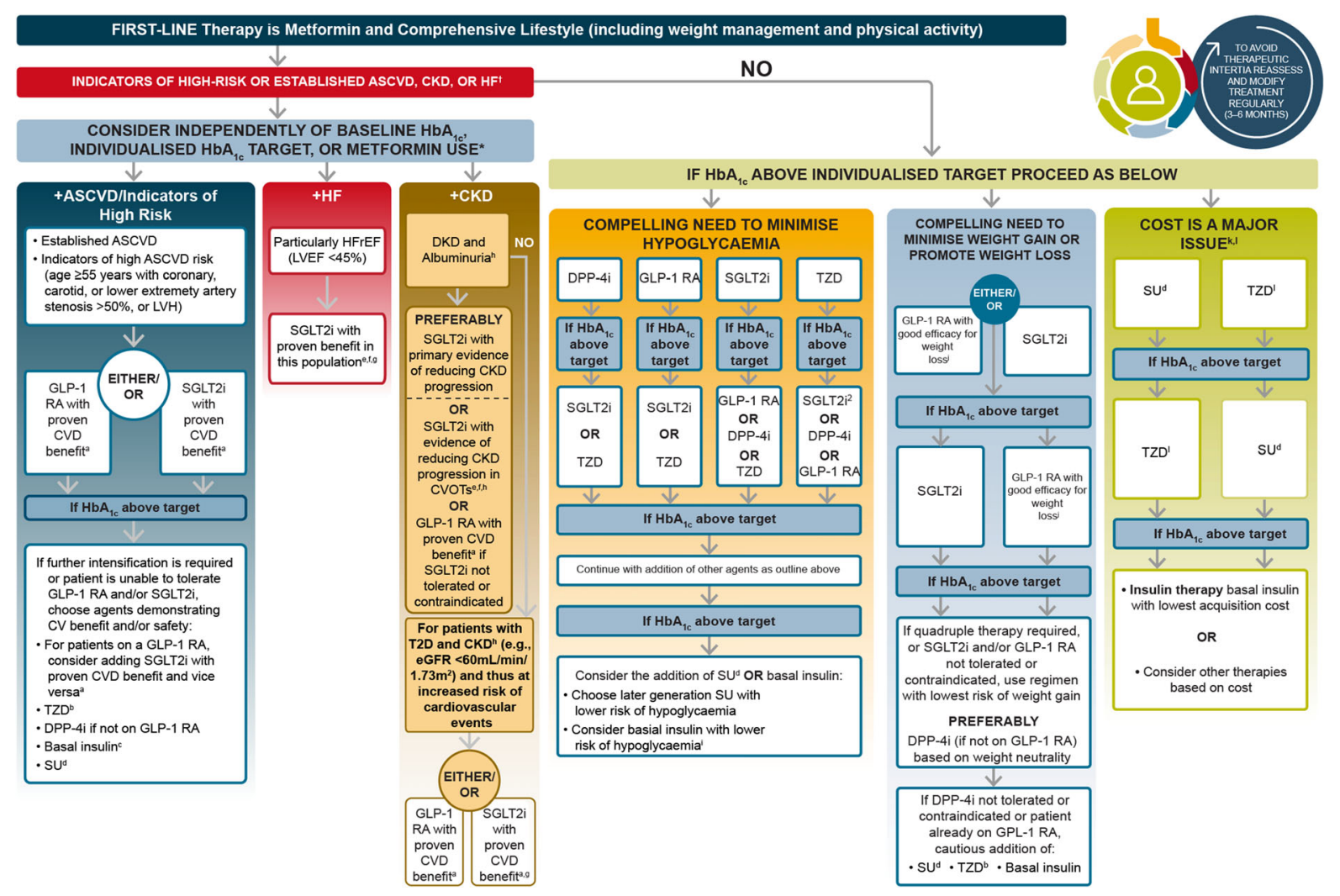

Fig. 6 ADA treatment algorithm for T2D management: an overall approach. Adapted from (CADA. Diabetes Care 2021;44:S111-24 [64] with permission from Springer. ${ }^{a}$ Proven CVD benefit means it has a label indication of reducing CVD events. 'bow dose may be better tolerated, though less well studied for CVD effects. ${ }^{c}$ Degludec or U100 glargine have demonstrated CVD safety. ${ }^{\mathrm{d}}$ Choose later generation $S U$ to lower risk of hypoglycaemia. Glimepiride has shown similar CV safety to DPP4i. ${ }^{\mathrm{e}} \mathrm{Be}$ aware that SGLT2i labelling varies by region and individual agent with regard to indicated level of eGFR for initiation and continued use. ${ }^{\mathrm{E}}$ Empagliflozin, canagliflozin and dapagliflozin have shown HF reduction and to reduce CKD progression in CVOTs. Canagliflozin and dapagliflozin have primary renal outcome data. Dapagliflozin and empagliflozin have primary HF outcome data. " Proven benefit means it has a label indication of reducing HF in this population. ${ }^{\mathrm{h}} \mathrm{Refer}$ to Sect. 11: microvascular complications and foot care. ${ }^{i}$ Degludec/glargine $\quad$ U300 $<$ glargine $\quad$ U100/detemir $<\mathrm{NPH}$

\section{Real-World Evidence of GLP-1 RA Therapy in T2D}

A substantial body of data in real-world settings supports the efficacy and safety of GLP-1 RAs insulin. $\quad$ 'Semaglutide $>$ liraglutide $>$ dulaglutide $>$ exenatide $>$ lixisenatide. ${ }^{\mathrm{k}}$ If no specific comorbidities (i.e. no established CVD, low risk of hypoglycaemia and low priority to avoid weight gain or no weight-related comorbidities). ${ }^{\mathrm{I}}$ Consider country-and region-specific cost of drugs. In some countries, TZDs are relatively more expensive and DPP4is relatively cheaper. ${ }^{\dagger}$ Actioned whenever these become new clinical considerations regardless of background glucoselowering medications. ${ }^{*}$ Most patients enrolled in the relevant trials were on metformin at baseline as glucose-lowering therapy. ASCVD atherosclerotic cardiovascular disease, CKD chronic kidney disease, DPP4i dipeptidyl peptidase 4 inhibitor, eGFR estimated glomerular filtration rate, GLP-1 RA glucagon-like peptide 1 receptor agonist, $\mathrm{HbA}_{1 \mathrm{c}}$ glycated haemoglobin, HF heart failure, HFrEF heart failure reduced ejection fraction, LVEF left ventricular ejection fraction, LVH left ventricular hypertrophy, SGLT2i sodium-glucose cotransporter 2 inhibitor, SU sulfonylurea, TZD thiazolidinedione, UACR urine albumin-to-creatinine ratio

evidenced from the randomised controlled trials (RCTs). The Association of British Clinical Diabetologists (ABCD) collected real-life data in the UK from 9020 people with T2D treated with the GLP-1 RAs exenatide and liraglutide to 
investigate the effectiveness in $\mathrm{HbA}_{1 \mathrm{c}}$ and weight reduction, and their associated AEs $[66,67]$. People with T2D receiving these drugs had a higher body weight and baseline $\mathrm{HbA}_{1 \mathrm{c}}$ than those from RCTs [67]. Both of these treatments were associated with a significant improvement in $\mathrm{HbA}_{1 \mathrm{c}}$ and reduction in weight at 3 and 6 months [67]. With regard to AEs, GI side effects were mostly reported (24\% and $16 \%$ in the exenatide and liraglutide groups, respectively). With regards to pancreatitis and acute renal failure, the numbers of cases were low in both the exenatide and liraglutide groups [67]. Of interest, in people treated with exenatide or liraglutide in combination with insulin, discontinuation with insulin was associated with a greater weight reduction and a lesser effect on $\mathrm{HbA}_{1 \mathrm{c}}$, compared with continuing with insulin [67].

A long-term retrospective study investigated the real-world effectiveness and safety of all the GLP-1 RAs available in Spain [68]. On the basis of hospital records from all people with T2D prescribed a GLP-1 RA treatment from 2009 to 2016, all GLP-1 RAs demonstrated significant reductions in $\mathrm{HbA}_{1 \mathrm{c}}$, fasting plasma glucose and body weight [68]. However, a high proportion of people with T2D discontinued GLP-1 RA treatments despite a low proportion of people with GI AEs. This was speculated to be due to a lack of effectiveness, resistance to injections and costs in some patients [68]. A retrospective cohort study in the USA investigated the 1-year treatment outcomes with GLP-1 RA according to baseline insulin use in people with T2D who initiated exenatide OW or liraglutide OD [69]. Clinical data from the Quintiles Electronic Medical Records Database was used to demonstrate that exenatide $\mathrm{OW}$ or liraglutide $\mathrm{OD}$ was associated with $\mathrm{HbA}_{1 \mathrm{c}}$ reduction and weight loss potential in people with $\mathrm{T} 2 \mathrm{D}$ regardless of baseline insulin use in the real-world setting [69].

With regards to the injectable GLP-1 RAs, treatment adherence is believed to be better in those with less frequent administration [70]. In retrospective studies in the real-world setting, treatment adherence was significantly better, respectively, with exenatide OW compared with exenatide BID [71, 72] or liraglutide OD [71-73], with dulaglutide OW compared with liraglutide OD or exenatide OW [74], and with liraglutide OD compared with exenatide BID [75]. However, there is no real-world evidence comparing the use of oral semaglutide with the injectable GLP-1 RAs yet.

\section{PRACTICAL CONSIDERATIONS}

Primary care clinicians tend to have more individual patient contact compared with other healthcare professionals, and thereby are well placed to initiate GLP-1 RAs and facilitate longterm adherence and persistence with these therapies. Specific barriers to prescription and optimal use of GLP-1 RAs include AEs, particularly GI side effects, s.c. injection and medical history of pancreatitis.

To address these barriers, a benefit/risk tool (Fig. 7) has been developed to provide a quick reference guide concerning specific clinical scenarios. This tool aims to provide clarity regarding common areas of confusion in clinical practice, helping clinicians to select appropriate individuals with T2D for GLP-1 RA therapies, in line with current available evidence and guidelines. The benefit/risk tool uses a traffic light system to help gauge risk and potential benefits in prescribing GLP-1 RAs, highlighting the various types of patients or clinical situations that are likely to be seen in a primary care setting:

- Low risk (green): robust evidence supports GLP-1 RA prescribing in these situations.

- Moderate risk (amber): prescribe GLP-1 RAs with caution (some evidence supports a benefit in these situations).

- High risk (red): do not prescribe GLP-1 RAs in these situations, because of lack of evidence, high risk of AEs or licence restrictions.

An evidence level has been assigned to each risk category, based on RCT and observational data, as well as NICE/SIGN guidelines and the licensed indication for each GLP-1 RA therapy. The level of evidence is scored according to the ADA Evidence-Grading System (Table 2) [78]. 


\begin{tabular}{|c|c|c|c|}
\hline Risk category & Clinical situation & Potential implications $[15,17,19,21,23,25,27]$ & Evidence level [70] \\
\hline \multirow{7}{*}{$\begin{array}{l}\text { Low risk } \\
\text { Evidence supports } \\
\text { GLP-1 RA prescribing }\end{array}$} & First-line (metformin intolerant) & & $A+B+E$ \\
\hline & Second-line to metformin & & $A+B+E$ \\
\hline & Third-line (add-on to second-line therapies) & & $A+B+E$ \\
\hline & Established CVD & & $A+B+E$ \\
\hline & Multiple $\mathrm{CV}$ risk factors & & $A+B+E$ \\
\hline & Overweight or obese (adjusted for ethnicity) & & $A+B+E$ \\
\hline & Vulnerable to the effects of hypglycaemia & & $A+B+E$ \\
\hline \multirow{11}{*}{$\begin{array}{l}\text { Moderate risk } \\
\text { Prescribing GLP-1 RAs } \\
\text { with caution }\end{array}$} & Combination with sulphonylurea & Hypoglycaemia & $A+B+E$ \\
\hline & Combination with basal insulin or multiple daily injections of insulin ${ }^{2}$ & DKA risk & $A+B+E$ \\
\hline & Frail/elderly/cognitive impairment & Hypoglycaemia, weight loss, sarcopenia & E \\
\hline & $\begin{array}{l}\text { Renal impairment } \\
\left(15 \mathrm{ml} / \mathrm{min} 1.73 \mathrm{~m}^{2} \leq \mathrm{eGFR}<90 \mathrm{~mL} / \mathrm{min} / 1.73 \mathrm{~m}^{2}\right.\end{array}$ & Licensed treatments only & $A+E$ \\
\hline & Diabetic retinopathy & $\begin{array}{l}\text { Increased risk of diabetic retinopathy complications in high-risk } \\
\text { patients (treated with insulin) and early worsening of } \\
\text { pre-existing diabetic retinopathy }\end{array}$ & $A+B+E$ \\
\hline & High $\mathrm{HbA}_{10}$ levels $(10.5 \% \text { or } 911 \mathrm{mmol} / \mathrm{mol})^{c}$ & $\begin{array}{l}\text { Potential for worsening of pre-existing diabetic retinopathy (see } \\
\text { above), DKA risk }\end{array}$ & E \\
\hline & $\mathrm{BMI}<25 \mathrm{~kg} / \mathrm{m}^{2}$ & DKA risk & E \\
\hline & History of gallstones ${ }^{d}$ & Risk of gallstone disease & $E$ \\
\hline & Acute pancreatitis $^{\circ}$ & Risk of severe pancreatitis and renal failure & $C+E$ \\
\hline & Heart failure New York Heart Association class IV & Not included in major clinical trials & E \\
\hline & Recent major surgery & Outside of licensed indication & E \\
\hline \multirow{8}{*}{$\begin{array}{l}\text { High risk } \\
\text { Do not prescribe } \\
\text { GLP-1 RAs }\end{array}$} & Allergic to medicines & Outside of licensed indication & N/A \\
\hline & T1D (diagnosed or suspected) & Outside of licensed indication & N/A \\
\hline & DKA & DKA risk & E \\
\hline & ESRD $\left(e G F R<15 \mathrm{~mL} / \mathrm{min} / 1.73 \mathrm{~m}^{2}\right)$ & Outside of licensed indication' & N/A \\
\hline & Severe GI disease & Risk of GI side effects & $E$ \\
\hline & Thyroid C-cell (medullary cell) cancer & $\begin{array}{l}\text { Contradiction in thyroid C-cell (medullary cell) cancer and } \\
\text { multiple endocrine neoplasia type } 2\end{array}$ & $\mathrm{C}+\mathrm{E}$ \\
\hline & Gastroparesis or severe gastroesophageal reflux disease & Risk of severe gastroesophageal reflux disease & E \\
\hline & $\begin{array}{l}\text { Pregnacy (or suspected pregnancy), planning pregnancy or } \\
\text { breastfeeding }\end{array}$ & Outside of licensed indication & N/A \\
\hline
\end{tabular}

Fig. 7 Benefit/risk tool: a reference guide regarding the use of GLP-1 RAs in patients with T2D. ${ }^{a}$ GLP-1 RA therapies should be prescribed with caution in people requiring rapid reduction in insulin dose or discontinuation of insulin, because of increased risk of DKA [76]; ${ }^{b}$ GLP-1 RA therapies should be prescribed with caution in people with diabetic retinopathy, because of increased risk of diabetic retinopathy complications in high-risk people (treated with insulin) and early worsening of pre-existing diabetic retinopathy, evidenced in the SUSTAIN 6 study (semaglutide OW) [37]; ${ }^{c} \mathrm{HbA}_{1 \mathrm{c}}$ levels should be monitored regularly and stop GLP-1 RA if elevated levels continue, following treatment initiation; ${ }^{\mathrm{d}} \mathrm{GLP}-1$ RAs should be prescribed with caution in people with gallstones, because of increased risk of gallstone diseases, evidenced in the LEADER study (liraglutide OD) [56]; ${ }^{\mathrm{e}}$ GLP-1 RAs should be prescribed with caution in people

\section{Patient Considerations}

Identifying the most suitable treatment for individuals with $\mathrm{T} 2 \mathrm{D}$ can aid treatment with acute pancreatitis, because of risk of severe pancreatitis and renal failure $[16,18,20,22,24,26,28,77]$, and exenatide BID is advised to be discontinued by MHRA if pancreatitis is diagnosed [77]; ${ }^{\mathrm{f}}$ To our knowledge, GLP-1 RAs are not recommended in patients with ESRD in European summary of product characteristics; however, there is no eGFR limitation for the use of GLP-1 RAs in some countries (e.g. for semaglutide in the USA). BID twice daily, BMI body mass index, CV cardiovascular, CVD cardiovascular disease, DKA diabetic ketoacidosis, eGFR estimated glomerular filtration rate, ESRD end-stage renal disease, GI gastrointestinal, GLP-1 RA glucagon-like peptide 1 receptor agonist, $\mathrm{HbA}_{1 \mathrm{c}}$ glycated haemoglobin, MHRA Medicines and Healthcare Products Regulatory Agency, N/A not applicable, OD once daily, OW once weekly, SU sulfonylurea, T1D type 1 diabetes, T2D type 2 diabetes

adherence. Firstly, substantial evidence from large CVOTs corroborates the use of GLP-1 RAs with $\mathrm{CV}$ benefits in patients with T2D at high risk of CV disease [34-37, 56, 79], which is also 
Table 2 ADA evidence-grading system for 'Standards of Medical Care in Diabetes' [78]

\begin{tabular}{ll}
\hline $\begin{array}{l}\text { Grade } \\
\text { level }\end{array}$ & Description \\
\hline A & $\begin{array}{c}\text { Clear evidence from well-conducted, } \\
\text { generalisable randomised controlled trials } \\
\text { that are adequately powered }\end{array}$ \\
B & $\begin{array}{l}\text { Supportive evidence from well-conducted } \\
\text { cohort studies }\end{array}$ \\
C & $\begin{array}{c}\text { Supportive evidence from poorly controlled or } \\
\text { uncontrolled studies }\end{array}$ \\
E & Expert consensus or clinical experience \\
\hline
\end{tabular}

Where data are conflicting or lacking, advice is provided that is based on expert opinion and experience in T2D management

$A D A$ American Diabetes Association

in line with the up-to-date NICE, SIGN and ADA guidelines described above. Secondly, on the basis of the weight loss potential of this class of agents, GLP-1 RAs are suitable for people with T2D who would benefit from weight reduction. Thirdly, for those with concerns about s.c. injections, including pain, fear of needles, burden and inconvenience, oral semaglutide OD could be selected by primary care clinicians to ease such concerns.

\section{Injection Technique}

Medical and/or nursing staff should be prepared to show patients the range of injection devices and assess their understanding and ability to use the agreed device. Injections sites and the importance of rotating the site, along with needle safety, storage, and disposal, should be discussed. Injection pens are designed to be easy to use; however, if individuals are uncertain about injection technique, clinicians should provide additional training and demonstration. This has been successfully delivered via virtual consultation using videos and supporting materials during Covid-19. All of the injectable GLP-1 RAs are delivered via pre-filled injection pens $[16,18,20,22,26]$, except for exenatide $\mathrm{OW}$, for which the powder and the solvent from two chambers should be mixed in the pre-filled pen prior to injection [24]. It is worth noting that the dulaglutide OW injection device was preferred to the semaglutide OW [80] and liraglutide OD [81] injection devices owing to its greater ease of use. Furthermore, the pen device of dulaglutide OW has a concealed needle which may be considered preferable in people reporting minor forms of needle phobia. However the usability study (PREFER), in which the injection devices of dulaglutide OW and semaglutide OW were compared, had a number of limitations, including the devices being used once only, injections being performed into an injection pad rather than participants, and the limited generalisability outside of the USA [80]. Furthermore, there were no differences in treatment satisfaction between dulaglutide OW and semaglutide OW as evidenced in the long-term trial SUSTAIN 7 [82]. To summarise, when prescribing a treatment, clinicians should consider injection device preference as well as the efficacy, safety and other important treatment attributes.

\section{Safety Considerations}

Contraindications to the use of GLP-1 RAs must be considered when making a prescribing decision. In patients with gastroparesis or severe gastro-oesophageal reflux disease, GLP-1 RAs should be used with close monitoring and dose adjustments as needed [83]. Patients who experience GI side effects should be advised to have frequent and smaller meals, and drink plenty of fluids to avoid dehydration. Although it is not a contraindication to use GLP-1 RAs in people with a history of pancreatitis, the summary of product characteristics of these therapies have included warnings concerning the risk of acute pancreatitis [16, 18, 20, 22, 24, 26, 28]; therefore, primary care clinicians should refer to the relevant summary of product characteristics when making prescribing decisions and consider taking specialist advice.

Real-world studies suggest that 12-month discontinuation rates for GLP-1 RA therapy vary 
between $29.5 \%$ and $47.7 \%$ [84, 85]. These rates appear to be higher than those reported in clinical trials, for example, $22.6 \%$ of patients prematurely discontinued therapy during the 24-month trial period in the SUSTAIN 6 trial of semaglutide [37], and $27.6 \%$ of randomised patients prematurely discontinued albiglutide during the 25-month trial period in the HARMONY trial [86]. It is possible that the higher discontinuation rates for GLP-1 RAs in realworld studies compared with clinical trials reflect the overall effect of cost for patients, side effects and patients and/or provider preferences regarding these GLP-1 RA therapies. Measures to support patient adherence are discussed in a later section.

\section{Dosing Considerations}

The recommended dose-escalation time period for GLP-1 RA is intended to improve GI tolerability to AEs such as nausea, vomiting and diarrhoea, which are common when initiating GLP-1 RAs [16, 18, 20, 22, 24, 26, 28]. To minimise these AEs, it is usually recommended to escalate the doses of GLP-1 RAs over a period of time, details of which are shown in Table 1. Dose escalation can be delayed by 1 week or altered to a more gradual dose escalation if GI intolerance is continued [12, 87], as extending time between dose escalations can help mitigate tolerability issues. Furthermore, extending the time before dose escalation may reduce the risk of retinopathy that is potentially increased because of a rapid glucose reduction [12]. Hypoglycaemia has been reported in people treated with GLP-1 RAs combined with SU and/ or insulin $[16,18,20,22,24,26,28]$; the dose of SU and/or insulin needs to be re-evaluated and may need to be reduced prospectively, in order to decrease this risk [7]. However, the dose reduction of SU and/or insulin should be in cautious stepwise fashion to avoid diabetic ketoacidosis, as per the drug safety update from the Medicines and Healthcare products Regulatory Agency [88].

\section{Adjunct Lifestyle Modification, Dietary and Physical Activity}

Lifestyle modification, dietary and physical activity are considered first-line interventions for people with T2D [41, 63, 65]. In addition, all of the GLP-1 RAs are indicated to be used as an adjunct to diet and exercise to improve glycaemic control in patients with T2D. Particularly, for people with T2D who are obese or overweight, a $5-10 \%$ weight loss of initial body weight has been shown to be beneficial [12]. A pilot study investigating the metabolic impact of intensive lifestyle intervention has shown that an intensive lifestyle programme consisting of structured educational group sessions and individual appointments can achieve sustained lifestyle improvement and weight loss in people with new onset of T2D without the need for oral glucose-lowering treatments [89]. Therefore, maintaining a healthy lifestyle and performing regular physical activity should be consistently advised to people with T2D.

\section{Measures to Support Adherence}

RCTs have demonstrated that GLP-1 RAs are an efficacious drug class and real-world evidence supports that this translates into real-word effectiveness. However, the RCT performance and outcomes are not always reflected in realworld studies, in part because of lower adherence and greater heterogeneity of population [90]. There is evidence that dosing frequency and single or multi-dose pens (for injections), efficacy and side effects are the most influential drivers of treatment preference [91-93]. Therefore, primary care clinicians can positively impact adherence by prescribing simple regimens, i.e. those with less dosing frequency, easy-to-use injection devices for injectable GLP1 RAs or oral formulation semaglutide. However, they also need to consider the administration method of oral semaglutide-it is advised be taken with an empty stomach and swallowed whole with up to $120 \mathrm{~mL}$ water; individuals should wait at least $30 \mathrm{~min}$ before eating, drinking or taking other oral medicinal products [28]. Clinicians should openly explain 
the benefits and potential AEs of treatments, consider optimising lifestyle measures, such as keeping well hydrated and small meal sizes, and build good supportive relationships with their patients. Furthermore, adequate discussion between clinicians and their patients allows a patient-centred treatment plan to be developed, so that optimal adherence is more likely to be achieved [70].

\section{Education and Counselling for People Considering a GLP-1 RA}

People with T2D who are considering a GLP-1 RA should be adequately informed about the mode of action and expected benefits, including $\mathrm{HbA}_{1 \mathrm{c}}$ and weight reductions, and if appropriate, reduced CV risk associated with GLP-1 RAs. Clinicians should also explain the possible AEs and management strategies, e.g. eating smaller meals more frequently and stopping when starting to feel full could ease the postprandial fullness, nausea and worsening of gastro-oesophageal reflux disease.

GLP-1 RA therapy is associated with a low risk of hypoglycaemia [15-28], which means that in the UK, routine declaration to the Driver and Vehicle Licensing Agency (DVLA) is not required unless there is history of hypoglycaemia or significant eye-related or circulatory problems [94]. Clinicians should check that drivers with T2D understand when they must not drive, when they may continue to drive subject to medical advice, and when they must inform the relevant governing body in their country of their condition.

\section{Monitoring and Review}

Clinicians should arrange appropriate monitoring and review for people with T2D who are treated with GLP-1 RAs. At 3 and 6 months, $\mathrm{HbA}_{1 \mathrm{c}}$, body weight and estimated glomerular filtration rate should be assessed, and any other medications that have been discontinued or reduced should be re-evaluated. Compliance, tolerance and lifestyle of people with T2D should also be revisited.

\section{Sick-Day Rules [95, 96]}

When people with T2D are unwell, they should contact their diabetes team if they are unsure about what to do. They should keep hydrated, eat little and often, monitor their blood glucose levels if possible, and temporarily pause GLP-1 RA treatment during any intercurrent dehydrating illness. The GLP-1 RA can be restarted when they are eating and drinking normally. If people with T2D are suffering from vomiting, drowsy, unable to keep fluids down and/or have persistent diarrhoea, medical help should be sought immediately.

\section{Virtual Consultations During the COVID- 19 Pandemic}

Virtual consultations, as the commonest service adaptation arising from the Covid-19 pandemic, can be used in primary care settings for initial and many follow-up appointments. Undoubtedly, the use of an online form, healthrelated app, phone and video calls can save time, provide convenience for both clinicians and patients, and significantly reduce face-toface contacts for both patients and clinicians. To ensure a satisfying outcome, several factors should be considered. Firstly, prior to any virtual consultations, clinicians should understand an individual's contact preferences, map the patient journey and suitably inform them about the technologies and processes involved. Vulnerable groups should be particularly focused on to ensure fair access. Secondly, during a virtual consultation, advice and information should be tailored to the individual patient and clinicians should check their level of understanding and agreement of treatment plans. It should always be considered whether a clinical examination or tests are required prior to prescribing medicines. Thirdly, after the virtual consultation, clinicians should ensure that patients have adequate take-home information and have access to further appointments. 


\section{FUTURE PERSPECTIVES OF GLP-1 RA USE IN PEOPLE WITH T2D}

People with T2D are at higher risk of CV events compared with those without T2D, and CV disease is the major cause of death in people with T2D [97]. In addition, concern has been raised about the $\mathrm{CV}$ safety of glucose-lowering therapies. As a result, current guidelines have shifted focus to reducing CV risk in people with T2D [41, 63, 65]. Therefore, GLP-1 RAs with CV benefit may hold future therapeutic promise in people with T2D. Furthermore, the newly available oral semaglutide-the first oral formulation of GLP-1 RA for the treatment of T2D [98] — has shown efficacy, safety and tolerability in a number of studies [35, 44-51]. Indeed, oral semaglutide has the potential to overcome many of the clinician and patient barriers surrounding previous and current injectable GLP-1 RA treatments.

\section{CONCLUSIONS}

GLP-1 RA therapies are effective treatment options for people with T2D, achieving $\mathrm{HbA}_{1 \mathrm{c}}$ reductions, weight loss and potential CV efficacy, as monotherapy or as add-on to other glucose-lowering therapies. This review provides a summary of clinical evidence and practical guidance to primary care clinicians and aids the initiation and monitoring of GLP-1 RAs to ensure more patients achieve desired clinical outcomes.

\section{ACKNOWLEDGEMENTS}

Funding. This review was funded by Novo Nordisk Inc. (Crawley, Gatwick, UK), which also reviewed the manuscript for medical accuracy and funded the journal's Rapid Service.

Authorship. All named authors meet the International Committee of Medical Journal Editors (ICJME) criteria for authorship for this article, take responsibility for the integrity of the work as a whole, and have given their approval for this version to be published.

Authorship Contributions. All authors contributed to the concept and design of this review and approved the final draft of this manuscript.

Medical Writing and Editorial Assistance. Writing and editorial support was provided by Jin Heppell, PhD, and Izabel James, MBBS, of Ashfield MedComms, and was funded by Novo Nordisk Inc. (Crawley, Gatwick, UK).

Disclosures. Kevin Fernando: Speaker honoraria: AstraZeneca, Sanofi, Novo Nordisk, and Eli Lilly.Stephen C. Bain: Lecture and advisory board fees: AstraZeneca, Boehringer Ingelheim, Eli Lilly, Merck Sharp \& Dohme, Novo Nordisk, Roche, Sanofi-Aventis; Shares: Glycosmedia, which carries sponsorship declared on site; Expert advice: All-Wales Medicines Strategy Group and the National Institute for Health and Care Excellence (UK).Patrick Holmes: Honoraria for teaching, travel, research and advisory board work from AstraZeneca, Eli Lilly and Novo Nordisk.Philip Newland Jones: Sponsorship for education events, research for, and educational speaking from, Abbott, AstraZeneca, Boehringer Ingelheim, Sanofi, Eli Lilly, Insulet, Novo Nordisk, MSD, Mylan, Napp, Servier and Takeda.Dipesh C. Patel: Lecture, educational and advisory related honoraria from AstraZeneca, Boehringer Ingelheim, Janssen, Lilly, Napp Pharmaceuticals, Novo Nordisk, Sanofi, MSD and Takeda; Chair, Association of British Clinical Diabetologists.

Compliance with Ethics Guidelines. This article is based on previously conducted studies and does not contain any studies with human participants or animals performed by any of the authors.

Data Availability. Data sharing is not applicable to this article as no datasets were generated or analysed during the current study. 
Open Access. This article is licensed under a Creative Commons Attribution-NonCommercial 4.0 International License, which permits any non-commercial use, sharing, adaptation, distribution and reproduction in any medium or format, as long as you give appropriate credit to the original author(s) and the source, provide a link to the Creative Commons licence, and indicate if changes were made. The images or other third party material in this article are included in the article's Creative Commons licence, unless indicated otherwise in a credit line to the material. If material is not included in the article's Creative Commons licence and your intended use is not permitted by statutory regulation or exceeds the permitted use, you will need to obtain permission directly from the copyright holder. To view a copy of this licence, visit http://creativecommons.org/licenses/by$\mathrm{nc} / 4.0 /$.

\section{REFERENCES}

1. Carls GA-O, Huynh J, Tuttle E, Yee J, Edelman SV. Achievement of glycated hemoglobin goals in the US remains unchanged through 2014. Diabetes Therapy. 2017;8:863-73.

2. Stone MA, Charpentier G, Doggen K, Kuss O, et al. Quality of care of people with type 2 diabetes in eight European countries: findings from the Guideline Adherence to Enhance Care (GUIDANCE) study. Diabetes Care. 2013;36:2628-38.

3. Okemah JA-O, Peng J, Quiñones M. Addressing clinical inertia in type 2 diabetes mellitus: a review. Adv Ther. 2018;35:1735-45.

4. Rushforth B, McCrorie C, Glidewell L, Midgley E, Foy R. Barriers to effective management of type 2 diabetes in primary care: qualitative systematic review. Br J Gen Pract. 2016;66: e114.

5. Chudasama YV, Gillies CL, Zaccardi F, et al. Impact of COVID-19 on routine care for chronic diseases: a global survey of views from healthcare professionals. Diabetes Metab Syndr. 2020;14:965-7.

6. Nauck M. Incretin therapies: highlighting common features and differences in the modes of action of glucagon-like peptide- 1 receptor agonists and dipeptidyl peptidase-4 inhibitors. Diabetes Obes Metab. 2016;18:203-16.
7. Lyseng-Williamson KA. Glucagon-like peptide-1 receptor agonists in type 2 diabetes: their use and differential features. Clin Drug Investig. 2019;39: 805-19.

8. Nauck MA, Kleine N, Orskov C, Holst JJ, Willms B, Creutzfeldt W. Normalization of fasting hyperglycaemia by exogenous glucagon-like peptide 1 (7-36 amide) in type 2 (non-insulin-dependent) diabetic patients. Diabetologia. 1993;36:741-4.

9. Merchenthaler I, Lane M, Shughrue P. Distribution of pre-pro-glucagon and glucagon-like peptide-1 receptor messenger RNAs in the rat central nervous system. J Comp Neurol. 1999;403:261-80.

10. Pyke C, Heller RS, Kirk RK, et al. GLP-1 receptor localization in monkey and human tissue: novel distribution revealed with extensively validated monoclonal antibody. Endocrinology. 2014;155: 1280-90.

11. Hinnen D. Glucagon-like peptide 1 receptor agonists for type 2 diabetes. Diabetes Spectrum. 2017;30:202-10.

12. Seidu S, Cos X, Brunton S, et al. A disease state approach to the pharmacological management of type 2 diabetes in primary care: a position statement by Primary Care Diabetes Europe. Prim Care Diabetes. 2020. https://doi.org/10.1016/j.pcd.2020. 05.004 .

13. Meier JJ. GLP-1 receptor agonists for individualized treatment of type 2 diabetes mellitus. Nat Rev Endocrinol. 2012;8:728-42.

14. Shah M, Vella A. Effects of GLP-1 on appetite and weight. Rev Endocr Metab Disord. 2014;15:181-7.

15. Byetta. Summary of product charateristics. 2020. https://www.ema.europa.eu/en/documents/pro duct-information/byetta-epar-product-information_en.pdf. Accessed 14 Sep 2020.

16. Byetta. Summary of product characteristics. 2021. https://www.medicines.org.uk/emc/product/286/ smpc\#gref. Accessed 14 Sep 2020.

17. Lyxumia. Summary of product charateristics. 2021. https://www.ema.europa.eu/en/documents /product->information/lyxumia-epar-product-information_en.pdf. Accessed 14 Sep 2020.

18. Lyxumia. Summary of product characteristics. 2020. https://www.medicines.org.uk/emc/product/ 2965/smpc. Accessed 14 Sep 2020.

19. Victoza. Summary of product characteristics. 2020. https://www.ema.europa.eu/en/documents /product-information/victoza-epar-product-information_en.pdf. Accessed 14 Sep 2020. 
20. Victoza. Summary of product characteristics. 2020. https://www.medicines.org.uk/emc/product/6585. Accessed on 14 September 2020.

21. Trulicity. Summary of product charateristics. 2020. https://www.ema.europa.eu/en/documents /product-information/trulicity-epar-product-information_en.pdf. Accessed 14 Sep 2020.

22. Trulicity. Summary of product characteristics. 2020. https://www.medicines.org.uk/emc/product/7482/ smpc. Accessed 14 Sep 2020.

23. Bydureon. Summary of product charateristics. 2020. https://www.ema.europa.eu/en/documents /product-information/bydureon-epar-product-information_en.pdf. Accessed 14 Sep 2020.

24. Bydureon. Summary of product characteristics. 2020. https://www.medicines.org.uk/emc/product/ 3650/smpc. Accessed 14 Sep 2020.

25. Ozempic. Summary of product charateristics. 2020. https://www.ema.europa.eu/en/documents /product-information/ozempic-epar-product-information_en.pdf. Accessed 14 Sep 2020.

26. Ozempic. Summary of product characteristics. 2020. https://www.medicines.org.uk/emc/product/ 9748/smpc. Accessed 14 Sept 2020.

27. Rybelsus. Summary of product characteristics. 2020. https://www.ema.europa.eu/en/documents /product-information/rybelsus-epar-product-information_en.pdf. Accessed 14 Sep 2020.

28. Rybelsus. Summary of product characteristics. 2020. https://www.medicines.org.uk/emc/product/ 11507. Acessed on 14 Sep 2020.

29. Jensen L, Helleberg H, Roffel A, et al. Absorption, metabolism and excretion of the GLP-1 analogue semaglutide in humans and nonclinical species. Eur J Pharm Sci. 2017;104:31-41.

30. Farmer RE, Beard I, Raza SI, et al. Prescribing in type 2 diabetes patients with and without cardiovascular disease history: a descriptive analysis in the UK CPRD. Clin Ther. 2021. https://doi.org/10.1016/ j.clinthera.2020.12.015.

31. Funck KA-O, Knudsen JA-O, Hansen TA-O, Thomsen RA-O, Grove EA-O. Real-world use of cardioprotective glucose-lowering drugs in patients with type 2 diabetes and cardiovascular disease: a Danish nationwide cohort study, 2012 to 2019. Diabetes Obes Metabol. 2020;23:520-9.

32. Fadini Gian P, Frison V, Simioni N, et al. Changes in the prescription of glucose-lowering medications in patients with type 2 diabetes mellitus after a cardiovascular event: a call to action from the Datafile study. J Am Heart Assoc. 2019;8: e012244.

33. van den Heuvel JM, Farzan N, van Hoek M, Maitland-van der Zee A-H, Ahmadizar F. Mining treatment patterns of glucose-lowering medications for type 2 diabetes in the Netherlands. BMJ Open Diabetes Res Care. 2020;8: e000767.

34. Holman RR, Bethel MA, Mentz RJ, et al. Effects of once-weekly exenatide on cardiovascular outcomes in type 2 diabetes. N Engl J Med. 2017;377:1228-39.

35. Husain M, Birkenfeld AL, Donsmark M, et al. Oral semaglutide and cardiovascular outcomes in patients with type 2 diabetes. $\mathrm{N}$ Engl J Med. 2019;381:841-51.

36. Gerstein HC, Colhoun HM, Dagenais GR, et al. Dulaglutide and cardiovascular outcomes in type 2 diabetes (REWIND): a double-blind, randomised placebo-controlled trial. Lancet. 2019;394:121-30.

37. Marso SP, Bain SC, Consoli A, et al. Semaglutide and cardiovascular outcomes in patients with type 2 diabetes. N Engl J Med. 2016;375:1834-44.

38. Pfeffer MA, Claggett B, Diaz R, et al. Lixisenatide in patients with type 2 diabetes and acute coronary syndrome. N Engl J Med. 2015;373:2247-57.

39. Wysham $\mathrm{CH}$, Pilon $\mathrm{D}$, Ingham $\mathrm{M}$, et al. HBA1C control and cost-effectiveness in patients with type 2 diabetes mellitus initiated on canagliflozin or a glucagon-like peptide 1 receptor agonist in a real-world setting. Endocr Pract. 2018;24:273-87.

40. Waugh N, Cummins E, Royle P, et al. Newer agents for blood glucose control in type 2 diabetes: systematic review and economic evaluation. Health Technol Assess (Winch, Engl). 2010;14:1-248.

41. National Institute of Health and Care Excellence. type 2 diabetes in adults: management. 2015. https://www.nice.org.uk/guidance/ng28. Accessed July 142020.

42. Lambrinou E, Kyriakou M, Lakatamitou I, et al. An integrative review on facilitators and barriers in delivering and managing injectable therapies in chronic conditions: a part of the ACNAP project 'injectable medicines among patients with cardiovascular conditions.' Eur J Cardiovasc Nurs. 2020;19:663-80.

43. Amori RE, Lau J, Pittas AG. Efficacy and safety of incretin therapy in type 2 diabetes systematic review and meta-analysis. JAMA. 2007;298: 194-206.

44. Aroda VR, Rosenstock J, Terauchi Y, et al. PIONEER 1: randomized clinical trial comparing the efficacy 
and safety of oral semaglutide monotherapy with placebo in patients with type 2 diabetes. Diabetes Care. 2019;42:1724-32.

45. Mosenzon O, Blicher TM, Rosenlund S, et al. Efficacy and safety of oral semaglutide in patients with type 2 diabetes and moderate renal impairment (PIONEER 5): a placebo-controlled, randomised, phase 3a trial. Lancet Diabetes Endocrinol. 2019;7: 515-27.

46. Pieber TR, Bode B, Mertens A, et al. Efficacy and safety of oral semaglutide with flexible dose adjustment versus sitagliptin in type 2 diabetes (PIONEER 7): a multicentre, open-label, randomised, phase 3a trial. Lancet Diabetes Endocrinol. 2019;7:528-39.

47. Pratley R, Amod A, Hoff ST, et al. Oral semaglutide versus subcutaneous liraglutide and placebo in type 2 diabetes (PIONEER 4): a randomised, doubleblind, phase 3a trial. Lancet. 2019;394:39-50.

48. Rodbard HW, Rosenstock J, Canani LH, et al. Oral semaglutide versus empagliflozin in patients with type 2 diabetes uncontrolled on metformin: the PIONEER 2 trial. Diabetes Care. 2019. https://doi. org/10.2337/dc19-0883.

49. Yabe D, Nakamura J, Kaneto H, et al. Safety and efficacy of oral semaglutide versus dulaglutide in Japanese patients with type 2 diabetes (PIONEER 10): an open-label, randomised, active-controlled, phase 3a trial. Lancet Diabetes Endocrinol. 2020;8: 392-406.

50. Yamada Y, Katagiri H, Hamamoto Y, et al. Doseresponse, efficacy, and safety of oral semaglutide monotherapy in Japanese patients with type 2 diabetes (PIONEER 9): a 52-week, phase 2/3a, randomised, controlled trial. Lancet Diabetes Endocrinol. 2020;8:377-91.

51. Zinman BA-O, Aroda VA-O, Buse JB, et al. Efficacy, safety, and tolerability of oral semaglutide versus placebo added to insulin with or without metformin in patients with type 2 Diabetes: the PIONEER 8 trial. Diabetes Care. 2019;42:2262-71.

52. Frias JP, Bonora E, Nevarez Ruiz LA, et al. 357-OR: efficacy and safety of dulaglutide $3 \mathrm{mg}$ and $4.5 \mathrm{mg}$ vs. dulaglutide $1.5 \mathrm{mg}$ : 52 -week results from AWARD-11. Diabetes. 2020;69:357.

53. Moghissi ES. Treating patients with diabetes of long duration: GLP-1 receptor agonists and insulin in combination. J Am Osteopath Assoc. 2014;114: S22-9.

54. Blonde L, Jendle J, Gross J, et al. Once-weekly dulaglutide versus bedtime insulin glargine, both in combination with prandial insulin lispro, in patients with type 2 diabetes (AWARD-4): a randomised, open-label, phase 3, non-inferiority study. Lancet. 2015;385:2057-66.

55. Marre $M$, Shaw J, Brändle $M$, et al. Liraglutide, a once-daily human GLP-1 analogue, added to a sulphonylurea over 26 weeks produces greater improvements in glycaemic and weight control compared with adding rosiglitazone or placebo in subjects with type 2 diabetes (LEAD-1 SU). Diabetes Med. 2009;26:268-78.

56. Marso SP, Daniels GH, Brown-Frandsen K, et al. Liraglutide and cardiovascular outcomes in type 2 diabetes. N Engl J Med. 2016;375:311-22.

57. Nreu B, Dicembrini I, Tinti F, Mannucci E, Monami M. Pancreatitis and pancreatic cancer in patients with type 2 diabetes treated with glucagon-like peptide-1 receptor agonists: an updated meta-analysis of randomized controlled trials. Minerva Endocrinol. 2020. https://doi.org/10.23736/S03911977.20.03219-8.

58. Vilsbøll T, Bain SC, Leiter LA, et al. Semaglutide, reduction in glycated haemoglobin and the risk of diabetic retinopathy. Diabetes Obes Metab. 2018;20:889-97.

59. Vega-Hernandez G, Wojcik R, Schlueter M. Costeffectiveness of liraglutide versus dapagliflozin for the treatment of patients with type 2 diabetes mellitus in the UK. Diabetes Ther. 2017;8:513-30.

60. Barnett AH, Arnoldini S, Hunt BA-OX, Subramanian G, Hoxer CS. Switching from sitagliptin to liraglutide to manage patients with type 2 diabetes in the UK: a long-term cost-effectiveness analysis. Diabetes Obes Metabol. 2018;20:1921-7.

61. Bain SC, Hansen BB, Malkin SJP, et al. Oral semaglutide versus empagliflozin, sitagliptin and liraglutide in the UK: long-term cost-effectiveness analyses based on the PIONEER Clinical Trial Programme. Diabetes Therapy. 2020;11:259-77.

62. Gorgojo-Martínez JJ, Malkin SJP, Martín V, Hallén $\mathrm{N}$, Hunt B. Assessing the cost-effectiveness of a once-weekly GLP-1 analogue versus an SGLT-2 inhibitor in the Spanish setting: once-weekly semaglutide versus empagliflozin. J Med Econ. 2020;23:193-203.

63. Scottish Intercollegiate Guideline Network (SIGN). Pharmacological management of glycaemic control in people with type 2 diabetes. Edinburgh: SIGN '154' - as per SIGN permission guidelines. 2017. https://www.sign.ac.uk/assets/sign154.pdf. Accessed July 142020.

64. American Diabetes Association. 9. Pharmacologic approaches to glycemic treatment: standards of 
medical care in diabetes-2021. Diabetes Care. 2021;44:S111-24.

65. Buse JB, Wexler DJ, Tsapas A, et al. 2019 update to: management of hyperglycemia in type 2 diabetes, 2018. A consensus report by the American Diabetes Association (ADA) and the European Association for the Study of Diabetes (EASD). Diabetes Care. 2019. https://doi.org/10.2337/dci19-0066.

66. Association of British Clinical Diabetologists. ABCD Nationwide Liraglutide Audit. 2020. http://www. diabetologists-abcd.org.uk/GLP1_Audits/ Liraglutide_Audit.htm. Accessed 25 Sep 2020.

67. Ryder REJ, Thong KY. Findings from the Association of British Clinical Diabetologists (ABCD) nationwide exenatide and liraglutide audits. In: Vora J, editor. Hot topics in diabetes. 5th ed. London: Springer; 2012. p. 49-61.

68. Tofé S, Argüelles I, Mena E, et al. Real-world GLP-1 RA therapy in type 2 diabetes: a long-term effectiveness observational study. Endocrinol Diabetes Metabol. 2019;2: e00051.

69. Singhal M, Unni S, Schauerhamer M, Nguyen H, Hurd J, McAdam-Marx C. Real-world glycemic control from GLP-1RA therapy with and without concurrent insulin in patients with type 2 diabetes. J Manag Care Spec Pharm. 2017;23:267-75.

70. Giorgino F, Penfornis A, Pechtner V, Gentilella R, Corcos A. Adherence to antihyperglycemic medications and glucagon-like peptide 1-receptor agonists in type 2 diabetes: clinical consequences and strategies for improvement. Patient Prefer Adher. 2018;12:707-19.

71. Nguyen H, Dufour R, Caldwell-Tarr A. Glucagonlike peptide-1 receptor agonist (GLP-1RA) therapy adherence for patients with type 2 diabetes in a medicare population. Adv Ther. 2017;34:658-73.

72. Johnston SS, Nguyen H, Felber E, et al. Retrospective study of adherence to glucagon-like peptide-1 receptor agonist therapy in patients with type 2 diabetes mellitus in the United States. Adv Ther. 2014;31:1119-33.

73. Qiao Q, Ouwens MJ, Grandy S, Johnsson K, Kostev K. Adherence to GLP-1 receptor agonist therapy administered by once-daily or once-weekly injection in patients with type 2 diabetes in Germany. Diabetes Metab Syndr Obes. 2016;9:201-5.

74. Alatorre C, Fernández Landó L, Yu M, et al. Treatment patterns in patients with type 2 diabetes mellitus treated with glucagon-like peptide-1 receptor agonists: higher adherence and persistence with dulaglutide compared with once-weekly exenatide and liraglutide. Diabetes Obes Metabol. 2017;19:953-61.

75. Malmenäs $\mathrm{M}$, Bouchard $\mathrm{R}$, Langer J. Retrospective real-world adherence in patients with type 2 diabetes initiating once-daily liraglutide $1.8 \mathrm{mg}$ or twice-daily exenatide $10 \mu$ g. Clin Ther. 2013;35: 795-807.

76. Medicines and Healthcare products Regulatory Agency. GLP-1 receptor agonists; reports of diabetic ketoacidosis when concomitant insulin was rapidly reduced or discontinued. 2020. https://www.gov. uk/drug-safety-update/glp-1-receptor-agonistsreports-of-diabetic-ketoacidosis-whenconcomitant-insulin-was-rapidly-reduced-ordiscontinued. Accessed 25 Sep 2020.

77. Medicines and Healthcare products Regulatory Agency. Exenatide (Byetta $\mathbf{\nabla}$ ): risk of severe pancreatitis and renal failure. 2020. https://www.gov. uk/drug-safety-update/exenatide-byetta-risk-ofsevere-pancreatitis-and-renal-failure. Accessed 25 Sep 2020.

78. American Diabetes Association. Standards of Medical Care in Diabetes-2020 abridged for primary care providers. Clin Diabetes. 2020;38:10-38.

79. Hernandez AF, Green JB, Janmohamed S, et al. Albiglutide and cardiovascular outcomes in patients with type 2 diabetes and cardiovascular disease (Harmony Outcomes): a double-blind, randomised placebo-controlled trial. Lancet. 2018;392:1519-29.

80. Matza LS, Boye KS, Stewart KD, et al. Assessing patient PREFERence between the dulaglutide pen and the semaglutide pen: a crossover study (PREFER). Diabetes Obes Metab. 2020;22:355-64.

81. Matza LS, Boye KS, Currie BM, et al. Patient perceptions of injection devices used with dulaglutide and liraglutide for treatment of type 2 diabetes. Curr Med Res Opin. 2018;34:1457-64.

82. Pratley RE, Aroda VR, Lingvay I, et al. Semaglutide versus dulaglutide once weekly in patients with type 2 diabetes (SUSTAIN 7): a randomised, openlabel, phase $3 \mathrm{~b}$ trial. Lancet Diabetes Endocrinol. 2018;6:275-86.

83. Garber AJ, Handelsman Y, Grunberger G, et al. Consensus statement by the American Association of Clinical Endocrinologists and American College of Endocrinology on the comprehensive type 2 diabetes management algorithm-2020 executive summary. Endocr Pract. 2020;26:107-39.

84. Wilke T, Mueller S, Groth A, et al. Non-persistence and non-adherence of patients with type 2 diabetes mellitus in therapy with GLP-1 receptor agonists: a 
retrospective analysis. Diabetes Ther. 2016;7: $105-24$.

85. Weiss T, Carr RD, Pal S, et al. Real-world adherence and discontinuation of glucagon-like peptide-1 receptor agonists therapy in type 2 diabetes mellitus patients in the United States. Patient Prefer Adher. 2020;14:2337-45.

86. Ahren B, Johnson SL, Stewart M, et al. HARMONY 3: 104-week randomized, double-blind, placeboand active-controlled trial assessing the efficacy and safety of albiglutide compared with placebo, sitagliptin, and glimepiride in patients with type 2 diabetes taking metformin. Diabetes Care. 2014;37: 2141-8.

87. Romera I, Cebrián-Cuenca A, Álvarez-Guisasola F, Gomez-Peralta F, Reviriego J. A review of practical issues on the use of glucagon-like peptide- 1 receptor agonists for the management of type 2 diabetes. Diabetes Ther. 2019;10:5-19.

88. Medicines and Healthcare products Regulatory Agency. Drug safety update: GLP-1 receptor agonists: reports of diabetic ketoacidosis when concomitant insulin was rapidly reduced or discontinued. 2020. https://www.gov.uk/drugsafety-update/glp-1-receptor-agonists-reports-ofdiabetic-ketoacidosis-when-concomitant-insulinwas-rapidly-reduced-or-discontinued. Accessed 27 Oct 2020.

89. Begley J, Bowes A, Hart T, Zouwail S, Kerr D. Metabolic impact of a successful lifestyle intervention in patients with new onset type 2 diabetes; a pilot study. J Diabetes Res Clin Metabol. 2013. https://doi.org/10.7243/2050-0866-2-10.

90. Carls GS, Tuttle E, Tan R-D, et al. Understanding the gap between efficacy in randomized controlled trials and effectiveness in real-world use of GLP-1 RA and DPP-4 therapies in patients with type 2 diabetes. Diabetes Care. 2017;40:1469-78.
91. Qin L, Chen S, Flood E, et al. Glucagon-like peptide1 receptor agonist treatment attributes important to injection-naïve patients with type 2 diabetes mellitus: a multinational preference study. Diabetes Ther. 2017;8:321-34.

92. Qin L, Chen S, Flood E, et al. Glucagon-like peptide1 receptor agonist treatment attributes important to injection-experienced patients with type 2 diabetes mellitus: a preference study in Germany and the United Kingdom. Diabetes Ther. 2017;8:335-53.

93. Gelhorn HL, Poon J-L, Davies EW, Paczkowski R, Curtis SE, Boye KS. Evaluating preferences for profiles of GLP-1 receptor agonists among injectionnaïve type 2 diabetes patients in the UK. Patient Prefer Adher. 2015;9:1611-22.

94. Driver and Vehicle Licensing Agency. Diabetes mellits: assessing fitness to drive. 2020. https:// www.gov.uk/guidance/diabetes-mellitus-assessingfitness-to-drive. Accessed 27 Oct 2020.

95. Diabetes UK. Dealing with illness. 2020. https:// www.diabetes.org.uk/guide-to-diabetes/life-withdiabetes/illness. Accessed 27 Oct 2020.

96. National Institute for Health and Care Excellence. Clinical knowledge summary. Diabetes - type 2 August 2017. 2020. https://cks.nice.org.uk/topics/ diabetes-type-2/. Accessed 27 Oct 2020.

97. Einarson TR, Acs A, Ludwig C, Panton UH. Prevalence of cardiovascular disease in type 2 diabetes: a systematic literature review of scientific evidence from across the world in 2007-2017. Cardiovasc Diabetol. 2018;17:83. https://doi.org/10.1186/ s12933-018-0728-6.

98. Bucheit JD, Pamulapati LG, Carter N, Malloy K, Dixon DL, Sisson EM. Oral semaglutide: a review of the first oral glucagon-like peptide 1 receptor agonist. Diabetes Technol Ther. 2019;22:10-8. 